\title{
Von der Reichsunmittelbarkeit zum \\ Reichsfürstentum - Kontinuitäten und \\ Diskontinuitäten
}

\section{From being an intrinsic part of the Empire to an imperial principality - continuity and discontinuity}

Paul Vogt / paul.vogt@li-life.li

Director Emeritus of the Liechtensteinisches Landesarchiv

\begin{abstract}
The roots of the Imperial Principality of Liechtenstein reach back to the late Middle Ages. In 1342, the County of Vaduz came into being, and in 1379 its owners were granted important privileges of jurisdiction (freedom from foreign judges). From 1396 to 1719, imperial immediacy was confirmed more than 25 times by the emperors. From 1500, the sovereigns were recognized as imperial estates. Over some 300 years the dynasties changed five times. With the exception of the Princes of Liechtenstein, all of them were economically too weak to ensure continuity over a longer period of time. This was only possible for the Princes of Liechtenstein, who bought the domain of Schellenberg in 1699 and the County of Vaduz in 1712. Greater continuity and thus the centuries-long existence of the small but immediate county was made possible by the Holy Roman Empire, its laws and its institutions.
\end{abstract}

\section{Keywords}

Holy Roman Empire of the German Nation, Imperial Diet (Reichstag), imperial Circles (Reichskreise), Swabian Circle (Schwäbischer Kreis), imperial immediacy, imperial Estates (Reichsstände), County of Vaduz, Domain of Schellenberg, Imperial count, Peace of Westphalia, Privilege of legal domicile (Gerichtsstandsprivileg), sovereignty, High Justice (Blutgerichtsbarkeit), country's frontiers and Dominions (Landes- und Herrschaftsgrenzen), Helvetia, Habsburg 


\section{Einleitung}

Das Fürstentum Liechtenstein definiert und legitimiert sich stark über seine jahrhundertelange Geschichte. Es sieht sich - wie viele andere Staaten - als historischen Sonderfall, da es über fast 700 Jahre und immer wieder neue Konstellationen hinweg die Eigenständigkeit bewahren konnte: im Heiligen Römischen Reich als Grafschaft Vaduz, ab 1719 als Reichsfürstentum, ab 1806 als souveräner Staat zunächst im Rheinbund und dann ab 1815 im Deutschen Bund. Ab 1866 lehnte es sich sehr stark an Österreich-Ungarn an, ab 1923 schliesslich an die Schweiz. Die Eigenständigkeit war immer nur relativ, das kleine Land war auch in zentralen staatlichen Aufgaben immer auf die wohlwollende Kooperation mit Nachbarstaaten angewiesen.

Als historischer Sonderfall erscheint Liechtenstein aber nur in der Retrospektive: Wie konnte ein so kleines staatliches Gebilde alle Wendungen und Stürme der Geschichte überleben? In der historischen Einbettung, aus dem Blickwinkel der jeweiligen Zeit, verliert vieles seinen ausserordentlichen Anschein. Manchmal bietet einfach die Erkenntnis, dass Liechtenstein zu unbedeutend war, den Schlüssel zum Verständnis, wie und warum das alles so und nicht anders gekommen ist. Oder spitz formuliert: Je besser man die Geschichte versteht, desto weniger lässt sie sich für die Legitimation der liechtensteinischen Eigenstaatlichkeit „brauchen“ und „nutzen“.

Dieser Beitrag befasst sich mit den grundlegenden staatsrechtlichen Strukturen in der Zeit von 1342 (Entstehung der Grafschaft Vaduz) bis 1719 (Entstehung des Reichsfürstentums Liechtenstein). Diese Zeit war einerseits geprägt durch grosse Diskontinuitäten - etwa alle hundert Jahre kam es zu einem Wechsel der Dynastien, da diese nicht fähig waren, stabile, tragfähige Grundlagen zu schaffen. Die Herrschaften Vaduz und Schellenberg bestanden aus wenigen kleinen Dörfern, Städte fehlten überhaupt. Die Landesherren waren wirtschaftlich schwach und politisch von Habsburg abhängig. Für Kontinuität sorgte das Reich und die Reichsinstitutionen: Der Kaiser und die Institutionen des Heiligen Römischen Reichs verliehen dem reichsunmittelbaren Territorium Dauer und rechtliche Strukturen, die ein immer gefährdetes, aber doch einigermassen tragfähiges Fundament ergaben. Es war diese reichsrechtliche Stellung, die die reichsunmittelbare Grafschaft attraktiv machte, nicht der wirtschaftliche Nutzen. Die zentrale Frage in diesem Beitrag ist also, welche dauerhaften Strukturen und Rahmenbedingungen die Basis für das spätere Fürstentum legten.

Vorab eine Bemerkung zum Forschungsstand: Der Historische Verein für das Fürstentum Liechtenstein gibt seit 1934 das Liechtensteinische Urkundenbuch (LUB) heraus. In den vergangenen Jahrzehnten wurden für die Zeit vom Mittelalter bis 1510 sehr viele Quellen ediert. Trotz dieser immensen Grundlagenarbeit ist für die Zeit vor 1719 eine Quellenarmut zu beklagen. Die historische Forschung selber hat sich wenig mit der Zeit vor der Entstehung des Fürstentums Liechtenstein befasst. In vieler Hinsicht ist immer noch die „Geschichte des Fürstenthums Liechtenstein“ von Peter Kaiser aus dem Jahr 1847 massgeblich. ${ }^{1}$

1 Kaiser, Peter: Geschichte des Fürstenthums Liechtenstein: Nebst Schilderungen aus Chur-Rätien's Vorzeit, Chur 1847. Neu herausgegeben von Arthur Brunhart. Vaduz 1989. 


\section{Landesherrschaft und Reichsgewalt}

Unter „Landesherrschaft“ wird die Konzentration älterer, oft personengebundener Herrschaftsrechte (Gerichtsbarkeit, Regalien, Grundherrschaft, Leibherrschaft usw.) in der Hand des Landesherrn verstanden. Die Ausübung wichtiger Teile der Staatsgewalt wurde vom Kaiser an die Landesherren verliehen. Eine Abgrenzung vom Begriff „Landeshoheit" ist schwierig, auf jeden Fall hat „Landeshoheit" neben der lehensrechtlichen auch eine landrechtliche Komponente: Die hoheitlichen Rechte wurden vom Besitz eines Landes bzw. Territoriums abgeleitet. Herrschaft wurde zunehmend nicht mehr durch die personalen Bindung an den Lehens- bzw. Landesherrn, sondern aufgrund der Zugehörigkeit zu einem Territorium definiert und legitimiert.

Den Kern der landesherrlichen Gewalt bildete die Hochgerichtsbarkeit (auch Blutgerichtsbarkeit), sie berechtigte den Landesherren gegen die ihm unterworfenen Personen Gewalt auszuüben. „Stock und Galgen“ zeigten symbolisch, wer Herr im Lande war. ${ }^{2}$ Mord, Todschlag, Vergewaltigung und wiederholter Diebstahl wurden mit dem Tod bestraft werden. Die Ausübung der niederen Gerichtsbarkeit ${ }^{3}$ war für die Landesherrschaft nicht von entscheidender Bedeutung. Die Gerichtszugehörigkeit wurde im Mittelalter noch vorwiegend durch die personale Bindung an die Person des Landesherrn bestimmt, dann aber zunehmend durch die Zugehörigkeit zum Territorium. ${ }^{4}$

Zumindest in der Theorie blieb im Heiligen Römischen Reich der Kaiser oberster Gerichtsherr. Prinzipiell konnte er in die Ausübung der Gerichtsbarkeit durch die Landesherren eingreifen. Diese waren daher bemüht, den Kaiser zu einem Verzicht auf dieses Recht zu bewegen, um die ausschliessliche Gerichtszuständigkeit in ihren Herrschaften durchzusetzen. Das Evokationsrecht gab dem Kaiser das Recht, jeden nicht erledigten Gerichtsfall an sich zu ziehen und ein königliches Gericht mit dessen Behandlung zu beauftragen. Mit dem Privileg des „ius de non evocando“verzichtete der König auf dieses Recht zugunsten des Landesherrn. Damit wurde verhindert, dass Gerichtsstreitigkeiten einem fremden Gericht vorgelegt wurden. Überdies waren die Landesherren darauf bedacht, die Appellationsmöglichkeit an ein kaiserliches Gericht einzuschränken. Mit der Verleihung des „ius de non appellando“ wurde den Untertanen in einem Rechtsstreit die Möglichkeit verwehrt, gegen das Urteil eines landesherrlichen Gerichts an die obersten Reichsgerichte zu appellieren. Ausgenommen waren Fälle, in denen das Recht vom

2 Allgemein zur Entwicklung der Gerichtshoheit in der Region: Gschwend, Lukas und Georg Kramer: Gerichtshoheit und Landesherrschaft. Die Entwicklung der Gerichtshoheit in Churrätien unter besonderer Berücksichtigung der Verhältnisse in der Grafschaft Werdenberg. In: Werdenberger Jahrbuch, Bd. 19, 2006, S. 9-28.

3 Von niederen Gerichten wurden vor allem Frevel und Vergehen bestraft. Die Strafen bestanden in der Regel in Geldbussen, Prügel- oder Schandstrafen (z. B. Zurschaustellung der Verurteilten am Schandpfahl).

4 Die Gerichtsorganisation in Vaduz war komplex: Teilweise übten die „Gerichte“ (mit dem Landammann an der Spitze) die Gerichtsbarkeit aus, teilweise die landesherrlichen Beamten oder der Landesherr selber. Vor allem bei Grenzstreitigkeiten entschieden häufig Schiedsgerichte. Immer wieder beklagt wurden Eingriffe des Landgerichts Rankweil in die Gerichtsbarkeit. Frommelt, Fabian: „... darauf hab ich ylenz ain Gemaindt in der herrschafft Schellenberg zusamenn beruefft ... ". Zu den Gerichtsgemeinden Vaduz und Schellenberg 1350-1550. Unpublizierte Lizentiatsarbeit, Triesen 2000. 
Landesherrn offensichtlich verweigert oder eine Entscheidung verzögert wurde. Die ausschliessliche Gerichtszuständigkeit der Landesherren stärkte ihre Stellung, da alle Leute in seinen Herrschaften ihr Recht bei ihm bzw. seinen Gerichten suchen mussten.

Neben der Blutgerichtsbarkeit gab es weitere hoheitliche Rechte, die für die Landeshoheit konstitutiv waren: das Besteuerungsrecht, das Gebots- und Verbotsrecht, das Militäraufgebot und die Regalien (Jagd, Fischerei, Münzen, Bergwerke, Zoll, Geleit, Markt u.a.). Grundherrliche Rechte (verbunden mit verschiedenen Abgaben und Fronen) waren sowohl für die Landesherren wie für Klöster und weltliche Herren eine wichtige Einnahmequelle. Eine starke Bindung an den Landesherrn schuf die Leibeigenschaft: Die Untertanen mussten ihrem Landesherrn einen persönlichen Huldigungseid schwören, ihm treu und gehorsam zu sein, seinen Nutzen zu fördern und Schaden von ihm abzuwenden. Der Status als Leibeigene verpflichtete sie zu einer jährlichen Abgabe (Fasnachtshenne) und verbot die Auswanderung. Die Landesherren waren bestrebt, rechtliche Unterschiede zwischen ihren Untertanen (Freie - Leibeigene) zu nivellieren. ${ }^{5}$ Sonderrechte wie die der „freien Walser“ wurden aufgehoben. Zu erwähnen sind auch die Religionshoheit und die Kontrolle über die Ein- und Auswanderung - beide wurden territorial begründet. Der Landesherr bestimmte die Religionszugehörigkeit und erteilte - gegen finanzielle Abgaben - die Bewilligung für die Ein- und Auswanderung.

\section{Die Dynastien - ein kurzer Überblick}

Wolfgang Schefknecht stellt die schwierige Situation der Grafen im Schwäbischen Kreis zusammenfassend wie folgt dar: „Praktisch alle Familien waren katholisch. [...] Die schwäbischen Grafen waren überwiegend kaisernah. Fast alle grösseren Familien [...] entsandten jüngere Söhne nach Wien, wo sie wichtige Positionen einnahmen. Der Reichshofrat, die kaiserliche Kanzlei, die kaiserliche Armee und die Reichskirche boten ihnen Karrierechancen. Keine der Familien war so stark, dass sie die anderen hätte dominieren können. Kreis und Grafenkollegium waren für die schwäbischen Grafen Institutionen, die geeignet waren, ihre Position zu stärken. Dies erlangte besonders gegen Ende des 17. Jahrhunderts zunehmende Bedeutung, als sie wiederholt mit Rebellionen ihrer Untertanen zu kämpfen hatten, die infolge von Kriegen durch hohe Steuerlasten bedrängt wurden. [...] Eheschliessungen, Erbteilungen und Verkäufe führten zu [...] häufigen Änderungen bei den Territorien. Von den 29 gräflichen Territorien im Kreis des Jahres 1664 befanden sich lediglich noch fünf in denselben Händen wie 1521. Seit dem 16. Jahrhundert mussten sich die Grafen und Herren in verschiedener Hinsicht bedroht fühlen. Als kleine Reichsstände wurden sie während der frühen Neuzeit aufgrund ihrer mangelnden Konkurrenzfähigkeit im Territorialisierungsprozess fast ständig durch mächtige Nachbarn und durch finanzielle Probleme bedroht. Die Furcht vor einem Abstieg in die Landsässigkeit und vor dem Verlust einzelner

5 So heisst es im sulzisch-hohenemsischen Urbar von 1614: „Wer in dise graffschaft haushablich ziecht, gibt der herrschafft, wie auch der gemaind den einzug und soll geben steür, tagmann, schniz, bethmist und faßnacht hennen, und thuen, wie ainander aigen mann." LIECHTENSTEIN. The Princely Collections, Hausarchiv Liechtenstein Wien (weiter HAL), Handschriften (weiter Hs) 7, S. 1-131; online: www.e-archiv.li/D48445. 
Gebietsteile und Rechte schwebte gleichsam wie ein Damoklesschwert über vielen reichsgräflichen

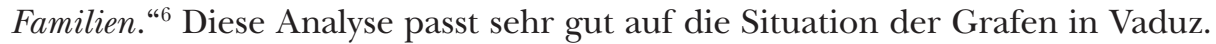

Die Dynastien im Rheintal waren - über einen langen Zeitraum betrachtet - nicht stabil, die Herrscherfamilien schafften es nicht, für eine ausreichende wirtschaftliche Grundlage und damit auch für Kontinuität zu sorgen. Einige konnten jedoch - vor allem nach dem Zerfall des Herzogtums Schwaben (1268) - von der Schwäche des Reichs profitieren und verstanden es, sich die Reichsunmittelbarkeit zu sichern. Das Resultat war eine starke Zersplitterung der Territorien in Südwestdeutschland.

Bei den Herrschaftswechseln findet man immer wieder das gleiche Muster: Eine hochadelige Familie kam aufgrund günstiger Umstände zu Reichtum und Ansehen. Erprobte Mittel waren insbesondere einträgliche Positionen im Umfeld des Kaisers, Militärunternehmertum, hohe kirchliche Ämter und berechnende Heiraten. Änderten sich die Voraussetzungen, fielen wichtige Einnahmen weg und die Familien gerieten in Schulden, was zum Niedergang der Dynastie führte. Bis auf die Fürsten von Liechtenstein hat es keine dieser Familien geschafft, die Herrschaften Vaduz und Schellenberg mehr als 100 Jahre zu halten. Hoch verschuldet mussten sie die beiden Herrschaften verpfänden und schliesslich verkaufen. Verkauft wurde an Verwandte, die infolge einer Heirat zum Familienumfeld gehörten und entsprechende Ansprüche geltend machen konnten. Soweit erkennbar verfolgte keine dieser Dynastien eine zielstrebige Territorialpolitik, in der Regel überwog das kurzfristige Gewinnstreben.

\section{Grafen von Werdenberg-Sargans zu Vaduz (1342-1416) ${ }^{7}$}

Um 1200 war ein grosser Teil des Gebiets im Rheintal von Graubünden bis zum Bodensee im Besitz der Grafen von Montfort. Durch wiederholte Erbteilungen wurde dieser umfangreiche Besitz aufgesplittert, oft umfasste eine Herrschaft nur noch wenige Dörfer. Bei jeder Teilung entstand eine weitere Linie der Grafen von Montfort und Werdenberg.

Um 1290 entstanden die Linien Werdenberg-Heiligenberg und Werdenberg-Sargans. Sie bewegten sich im engsten Gefolge der Habsburger, besetzten oft Reichsämter und betätigten sich als Militärunternehmer. 1342 teilte die Sarganser Linie den Besitz, wodurch die Grafschaft Vaduz entstand. Der Zweig Werdenberg-Sargans übernahm den links des Rheins liegenden Anteil mit der Grafschaft Sargans, der Zweig Werdenberg-Sargans-Vaduz den rechts des Rheins liegenden Teil mit den Herrschaften Vaduz, Sonnenberg, Blumenegg und dem südlichen Teil von Schellenberg. Die Vaduzer Linie erhielt einen vergleichsweise ansehnlichen Besitz mit aneinandergrenzenden Herrschaften, was zumindest verwaltungsmässig ein Vorteil hätte sein können.

6 Scheffknecht, Wolfgang: Kleinterritorium und Heiliges Römisches Reich. Der «Embsische Estat» und der Schwäbische Reichskreis im 17. und 18. Jahrhundert. Konstanz 2018. (Forschungen zur Geschichte Vorarlbergs. Neue Folge, Bd. 13.) S. 427-462, hier S. 201.

7 Burmeister, Karl Heinz: Werdenberg, von. In: Historisches Lexikon des Fürstentums Liechtenstein online (eHLFL), online: www.historisches-lexikon.li/Werdenberg. 
Bischof Hartmann IV. war nach dem Tod seines Bruders Heinrich (1397) alleiniger Landesherr in Vaduz. Er machte sich als kriegerischer und fehdelustiger Bischof einen Namen. Mit Habsburg war er mal verbündet, mal in Kämpfe und politische Auseinandersetzungen verwickelt. Durch seine Fehden geriet er zunehmend in wirtschaftliche Schwierigkeiten. Die Brüder Heinrich V. (†1397) und Hartmann IV (†1416) mussten ihre Herrschaften nach und nach an ihre Stiefbrüder Ulrich Thüring IV. und Wolfhart IV. von Brandis verpfänden (1391 Blumenegg, 1396-1399 Vaduz und 1412 Sonnenberg). Bischof Hartmann besuchte 1414 bis 1416 noch das Konstanzer Konzil. Mit ihm starb die Vaduzer Linie der Grafen von Werdenberg aus, der Besitz ging an die Freiherren von Brandis.

\section{Freiherren von Brandis (1416-1510) ${ }^{8}$}

Die Freiherren von Brandis stammten ursprünglich aus dem Gebiet des heutigen Kantons Bern (Schweiz), verlegten aber im 14. Jahrhundert ihren Interessenschwerpunkt in den Bodenseeraum. Mit einer erfolgreichen Heiratspolitik, der skrupellosen Ausnutzung von kirchlichen Ämtern (u.a. Abt in Einsiedeln, Bischof von Konstanz) und riskanten Kreditgeschäften operierten sie im 14. Jahrhundert recht erfolgreich. Die Grafschaft Vaduz und die Herrschaften Sonnenberg, Blumenegg und Teile von Schellenberg konnten sie ab 1391 nach und nach von ihren Stiefbrüdern Heinrich V. und Bischof Hartmann übernehmen. Die Herrschaft Sonnenberg war allerdings nur von 1412 bis 1416 in ihrem Besitz, dann verloren sie diese an die Grafen von Werdenberg-Sargans. Mit dem Verlust von Sonnenberg ging jene Herrschaft verloren, die die verschiedenen Herrschaften der Brandis miteinander verband. Auf der anderen Seite konnten die Brandis bis 1437 zwei Erwerbungen machen, die beide an ihren Besitz angrenzten: im Norden den nördlichen Teil der Herrschaft Schellenberg und im Süden die Herrschaft Maienfeld. Mit diesen Erwerbungen war das Gebiet des heutigen Fürstentums in einer Hand vereint, nach dem Verkauf von Maienfeld an die Drei Bünde im Jahr 1509 waren die Grenzen des heutigen Fürstentums festgelegt.

Der Besitz der Brandis war eingeklemmt zwischen den Eidgenossen und den Habsburgern, entsprechend suchten sie sich immer auf beide Seiten abzusichern. Sie standen immer wieder in den Diensten der Habsburger, bemühten sich aber auch um gute Beziehungen zu den Eidgenossen (z.B. durch ein Burgrecht in Bern). Die Verdienste um den Kaiser wurden 1430 mit der Verleihung der „Brandisischen Freiheiten“ (Blutgerichtsbarkeit und Reichsunmittelbarkeit) belohnt. In der Folge konnten sie sich aber nicht aus den Kriegen zwischen den Eidgenossen und Habsburg heraushalten - und scheiterten daran. Für die Parteinahme für Österreich mussten sie sowohl im Alten Zürichkrieg (1439-1446) wie auch im Schwabenkrieg (1499) bitter büssen. Die Freiherren gerieten

8 Leonhard, Martin: Brandis, von. In: Historisches Lexikon der Schweiz(HLS), online: https://hls-dhs-dss. ch/de/articles/019602/2002-12-13/, aufgerufen am 12.4.2020; Stievermann, Dieter: Brandis, von. In: Historisches Lexikon des Fürstentums Liechtenstein online (eHLFL), URL: https://historisches-lexikon.li/ Brandis,_von, abgerufen am 12.4.2020. 
durch den Schwabenkrieg sowohl politisch wie auch wirtschaftlich in grosse Schwierigkeiten.

Da die letzten Freiherren von Brandis keine männlichen Nachkommen hatten, starb mit dem Churer Dompropst Johannes von Brandis die Dynastie aus. 1509 verkaufte er die Herrschaft Maienfeld an die Drei Bünde (heute Graubünden), 1510 seine Herrschaften Vaduz, Schellenberg, Blumenegg für 12000 Gulden an seinen Neffen Rudolf von Sulz. Kaiser Maximilian hatte erwartet, dass diese Herrschaften an das Reich heimfallen würden, doch kam ihm Johannes durch den Verkauf der Herrschaften zuvor. ${ }^{9}$

\section{Grafen von Sulz (1510-1613) ${ }^{10}$}

Die Grafen von Sulz waren ein altes südwestdeutsches Grafengeschlecht, das im Dienst der Habsburger einflussreiche Reichsämter ausübte (u.a. Hofrichter in Rottweil). 1408 brachten sie die Grafschaft Klettgau durch eine Heirat mit einer Erbtochter in ihren Besitz. Ab 1482 konnten sie ihren süddeutschen Besitz beträchtlich erweitern (1482 Tiengen, 1488 Jestetten, 1497 Küssaburg). 1510 - im Zenit ihrer Macht - konnte Graf Rudolf V. von Sulz die Herrschaften Vaduz, Schellenberg und Blumenegg von Johannes von Brandis erwerben. Der Interessenschwerpunkt des Hauses blieb in Südwestdeutschland, das Verwaltungszentrum war Tiengen. Dass der Erwerb des ehemaligen Herrschaftsbesitzes der Brandis einen enormen Prestigegewinn bedeutete, zeigt sich darin, dass das Wappen der Sulz um 1540 gemehrt bzw. geviert wurde (Sulz mit Brandis).

Wie bei den Brandis brachte die politische und geographische Nähe zu Habsburg und die Nachbarschaft zur Eidgenossenschaft die Familie wiederholt in eine schwierige politische Situation. 1488 erwarben sie das Burgrecht in Zürich. Im Schwabenkrieg von 1499 spielten sie keine wichtige Rolle, vermutlich wegen des jugendlichen Alters von Graf Rudolf V. Aufgrund von Kriegen, Misswirtschaft und einem aufwendigen Lebensstil einerseits und zu kleinen Einnahmen aus dem Besitz andererseits gerieten die Sulz gegen Ende des 16. Jahrhunderts in eine enorme Verschuldung. 1599 erging ein Aufruf an alle Gläubiger, ihre Ansprüche anzumelden. Die Schulden wurden auf 315000 Gulden berechnet. Zur Schuldenregulierung wurde eine kaiserliche Kommission eingesetzt, die einer Zwangsverwaltung gleichkam. Graf Rudolf VII. musste 1603 zugunsten seines jüngeren Bruders Karl Ludwig abdanken, ${ }^{11}$ doch dieser konnte die finanzielle Situation auch nicht mehr sanieren. 1613 musste er Blumenegg für 150000 Gulden an das Kloster Weingarten, Vaduz und Schellenberg zusammen für 200000 Gulden an seinen späteren Schwiegersohn Graf Kaspar von Hohenems verkaufen. ${ }^{12}$

9 Stievermann, D.: Johannes von Brandis. In: eHLFL.

10 Noflatscher, Heinz: Sulz, von. In: Historisches Lexikon des Fürstentums Liechtenstein, online (eHLFL), URL: https://historisches-lexikon.li/Sulz,_von, abgerufen am 12. 4. 2020.

11 Seger, Otto: Aus den Zeiten des Herrschaftsüberganges von Brandis zu Sulz und von Sulz zu Hohenems. Jahrbuch des Historischen Vereins für das Fürstentum Liechtenstein 60, 1960, S. 21-70, hier S. 54 f.

12 Kaufvertrag vom 22. März 1613; online: www.e-archiv.li/D46143. 
In der Landesgeschichtsschreibung gelten die Jahre unter den Grafen von Sulz als "glückliche Zeiten“. Rudolf V. verhinderte, dass die Reformation in Vaduz Fuss fasste. Während der Bauernunruhen kam es 1525 zwar zu Unruhen, aber zu keinen Gewaltausbrüchen. Auf der Burg Vaduz wurden einige österreichische Landsknechte stationiert; ${ }^{13}$ das Ganze endete schliesslich „ohne Blutvergießen und schwere Strafen“. ${ }^{14}$ Rudolf V. kam den Untertanen bei den Fronen und Abgaben entgegen und konnte so die Untertanen beruhigen. Gemäss Peter Kaiser gewährte er „bedeutende Erleichterungen“: „Die Zinse derjenigen, die auf Herrschaftsgütern saßen, wurden herabgesezt, eben so die Tagwen oder Frohnden auf drei Tage im Jahr und jedem, der Tagwen that, wurde die Kost gegeben nach altem Brauch." ${ }^{15}$ Die Sulz standen in kaiserlichen Diensten und nahmen ihre Rechte als Landesherren mehrheitlich aus der Ferne wahr, was den Landschaften in ihrem Bestreben nach Selbstverwaltung entgegenkam. Die Landesherren delegierten hoheitliche Aufgaben teilweise an die beiden Landschaften, erliessen aber auch vermehrt neue Rechtsvorschriften. 1584 einigte sich Karl Ludwig von Sulz mit den Landschaften über eine neue Reichsteuer („Schnitz“), die ursprünglich auf fünf Jahre befristet sein sollte, dann aber zu einer permanenten Steuer wurde. Die beiden Landschaften setzten durch, dass die Anlage der Steuer allein ihre Sache war und sich die herrschaftlichen Beamten nicht einmischen durften. ${ }^{16}$ Vor dem Verkauf an Hohenems sollen die Landschaften Graf Karl Ludwig angeboten haben, ihm bei der Schuldentilgung zu helfen, falls dadurch der Herrschaftswechsel abgewendet würde. ${ }^{17}$

\section{Grafen von Hohenems (1613-1699/1712) ${ }^{18}$}

Die Grafen von Hohenems waren Besitzer der gleichnamigen Grafschaft in Vorarlberg. Als Söldnerführer, Beamte bzw. Vögte der Habsburger und nicht zuletzt dank hohen kirchlichen Ämtern kamen sie im 16. Jahrhundert zu Reichtum, Einfluss und Macht. Märk Sittich III. wurde 1561 Kardinal und 1562 Fürstbischof von Konstanz, Märk Sittich IV. 1612 Erzbischof von Salzburg, wo er sich als Bauherr einen Namen machte. Ihren Zenit erlebte die Dynastie, als Graf Kaspar 1613 die Herrschaften Vaduz und Schellenberg kaufte. Sein ehrgeiziges Ziel war die Errichtung eines Reichsfürstentums, das den grössten Teil des Rheintals umfassen sollte. Das wäre nur auf Kosten der Eidgenossen und Habsburger möglich gewesen wäre - es war ein kurzer Traum, der bald scheiterte. Nach dem Spanischen Erbfolgekrieg (1701-1714) versiegten die Einnahmen aus dem Söldnerwesen. Die Grafen blieben bei ihrem aufwendigen Lebensstil und

13 Frommelt, Fabian: Bauernkrieg. In: Historisches Lexikon des Fürstentums Liechtenstein, online (eHLFL): historisches-lexikon.li/Bauernkrieg,

14 Kaiser, P.: Geschichte, S. 324.

15 Kaiser, P.: Geschichte, S. 328.

16 Kaiser, P.: Geschichte, S. 338.

17 Noflatscher, H.: Sulz, von. In: eHLHL; online: https://historisches-lexikon.li/Sulz,_von.

18 Burmeister, K. H.: Hohenems (Ems), von. In: Historisches Lexikon des Fürstentums Liechtenstein online (eHLFL), URL: https://historisches-lexikon.li/Hohenems_(Ems),_von, abgerufen am 13. 4. 2020. 
machten Schulden. Unter anderem versuchten sie, sich mit Hexenprozessen wirtschaftlich zu sanieren. Aufgrund der Klagen von Untertanen beim Kaiser wurden die Hexenprozesse untersucht. Das Ergebnis war, dass alle Prozesse wegen Verfahrensmängeln für rechtswidrig erklärt wurden. Wegen der Misswirtschaft und der massiven Verschuldung wurden die Herrschaften unter kaiserliche Zwangsverwaltung gestellt. Die kaiserliche Kommission setzte den regierenden Grafen Ferdinand Karl schliesslich 1684 ab, der bald darauf in Gefangenschaft starb. Doch auch sein Nachfolger Jakob Hannibal III. war nicht fähig, einen Ausweg aus der Überschuldung zu finden. Letztlich blieb nur der Verkauf an Liechtenstein übrig (1699/1712).

Die Herrschaftszeit der Hohenems gilt in der liechtensteinischen Geschichtsschreibung als das „unglückliche Jahrhundert“. Im Vergleich zu ihren Vorgängern nahmen die Hohenems ihre landesherrlichen Rechte selbstbewusster wahr, was zwangsläufig zu Konflikten mit den Landschaften führte. Wegen der Steuern kam es zu jahrzehntelangen Auseinandersetzungen mit den Untertanen. Die Rechte der Landschaften in der Rechtsprechung wurden zurückgedrängt oder ganz aufgehoben. Das Maien- und Herbstzeitgericht, das zweimal jährlich auf einem offenen Platz unter dem Vorsitz des Landammanns stattgefunden hatte, wurde aufgehoben, und die Rechtsprechung auf die landesherrlichen Beamten übertragen, die dieser Aufgabe in der Burg Vaduz nachkamen. Die Landammänner konnten noch als Beisitzer mitwirken. Bei den Huldigungen für die Fürsten von Liechtenstein in den Jahren 1699, 1712 und 1718 forderten die Untertanen nachdrücklich die Wiedereinführung der sogenannten alten Landammannverfassung, doch liessen sich die Fürsten von Liechtenstein auf keine Verhandlungen ein.

\section{Die Reichsgrafschaft Vaduz - ihre Privilegien}

\section{Entstehung der Grafschafft Vaduz 1342}

Die Grafschaft entstand 1342 ohne kaiserliches Mitwirken durch die Teilung der Grafschaft Sargans. Da sich die beiden Brüder Hartmann und Rudolf von Werdenberg-Sargans offenbar nicht einigen konnten, wurde die Teilung durch ein Schiedsgericht vorgenommen. Dieses bestimmte, dass alles, was rechts des Rheins lag (Vaduz, Blumenegg, Nüziders/Sonnenberg), an Hartmann ging, und alles, was links des Rheins lag (Sargans), an Rudolf - offenbar ging man davon aus, dass die Grafschaft Sargans wie ein freies Eigen ohne Zustimmung des Kaisers geteilt werden konnte und dass auch die neue Grafschaft die vollen Rechte der alten Grafschaft besass. Der Rhein bildete quasi eine natürliche Grenze. Das Resultat dieser Teilung waren noch keine klar abgegrenzten Herrschaften, in denen alle Rechte beim Landesherrn lagen, sondern grob umrissene „Einfluss- und Interessenzonen“, die sich an Burgen und Städten orientierten. ${ }^{19}$ Innerhalb dieser Zonen konkurrierten die verschiedenen Herren um die Nutzungsrechte. Die Details, wer wo welche grundherrlichen Rechte geltend machen konnte (niedere

19 Frey, Stefan: Herrschaftsbildung vom 11. bis ins frühe 14. Jahrhundert. Jahrbuch des Historischen Vereins für das Fürstentum Liechtenstein 114, 2015, S. 69-87, hier S. 76. 


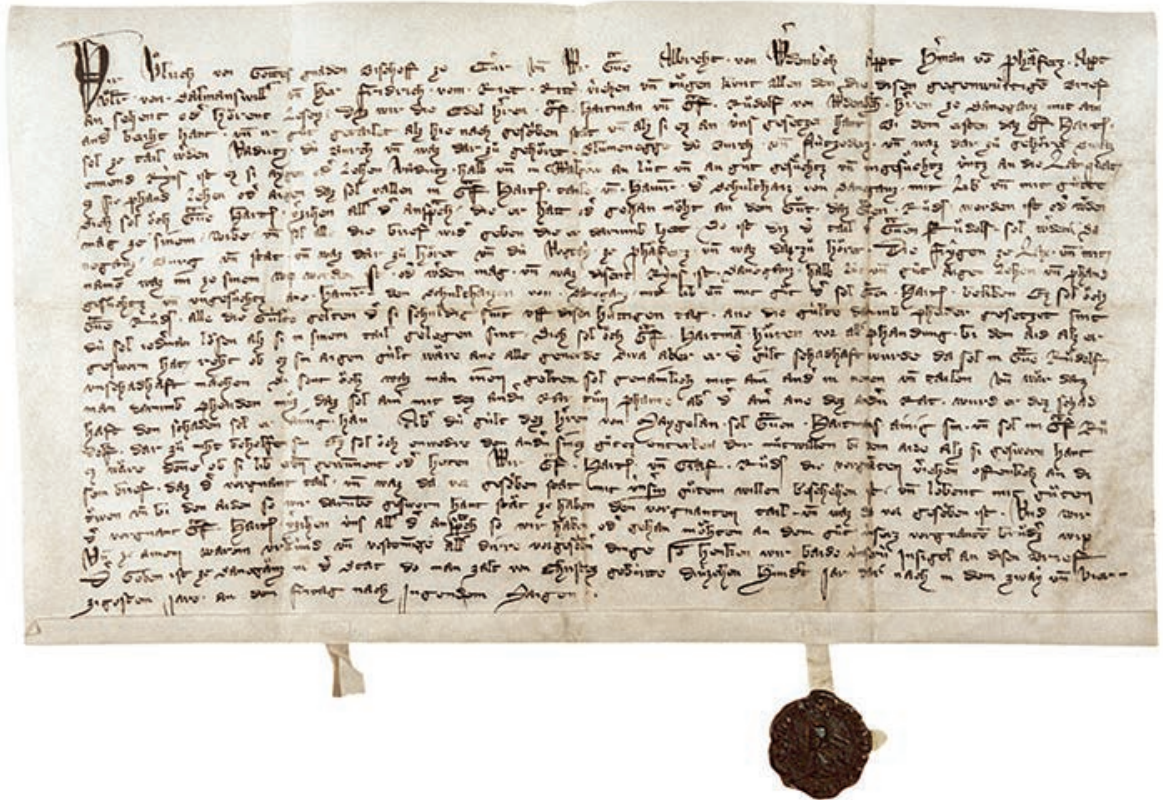

Urkunde vom 3. Mai 1342 betr. die Teilung der Grafschaft Sargans: Ein Schiedsgericht bestimmt, dass Graf Hartmann alles, was rechts des Rheins liegt, bekommt und sein Bruder Rudolf, was links des Rheins liegt. (Original: Bischöfliches Archiv Chur, Foto: Liechtensteinisches Landesarchiv, Vaduz.)

Gerichtsbarkeit, Jagd, Wälder, Mühlen etc.), wurden im Teilungsvertrag nicht geregelt und führten in der Folge wiederholt zu Konflikten, die nicht immer friedlich ausgetragen wurden.

\section{Gerichtsstandsprivileg von 1379}

1379 verlieh König Wenzel Graf Heinrich von Werdenberg-Sargans zu Vaduz ein Gerichtsstandsprivileg: Für Gerichtsfälle, in die Leute aus seinen Grafschaften involviert waren, lag die Zuständigkeit allein beim Gericht des Grafen; fremde Gerichte durften nicht angerufen werden (Freiheit vor fremden Richtern). Als fremde Gerichte wurden speziell das Hofgericht in Rottweil und die kaiserlichen Landgerichte erwähnt. Das Verbot, fremde Richter anzurufen, schränkte auch die Appellationen an ein königliches Hof- oder Landgericht ein. An die Reichsgerichte konnten nur Untertanen gelangen, denen die Grafen oder ihre Richter „offensichtlich und öffentlich“ das Recht versagten. ${ }^{20}$

In der Urkunde wird die Blutgerichtsbarkeit nicht erwähnt, da der Graf aber das Recht der ausschliesslichen Gerichtsbarkeit in seinen Herrschaften erhielt, war die

20 Urkunde vom 16. Oktober 1379, Liechtensteinisches Urkundenbuch I (im Folgenden LUB), Teil I, Bd. 5, Nr. 467, online: www.e-archiv.li/D48081. 


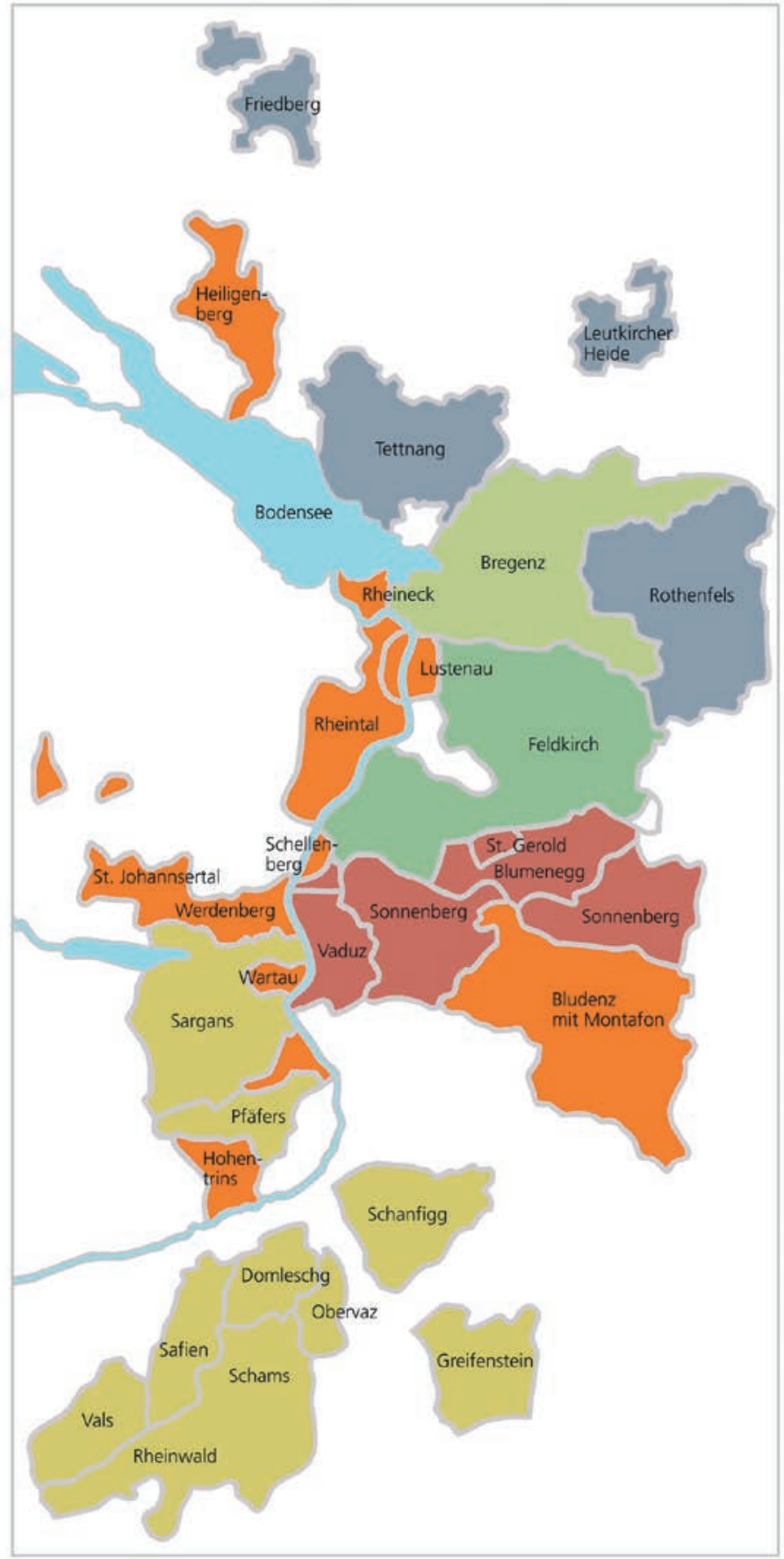

Werdenberg-Heiligenberg

Werdenberg-Sargans

Werdenberg-Sargans-Vaduz

Montfort-Feldkirch

Montfort-Bregenz

Montfort-Tettnang

Der Herrschaftsbesitz der Grafen von Werdenberg war nach den diversen Erbteilungen, aber auch durch verschiedene Erwerbungen um 1350 stark zersplittert.

(Kartenentwurf: Paul Vogt, Gestaltung: Evelyne Bermann.) 
Blutgerichtsbarkeit inkludiert. Die Urkunde von 1379 enthält ausserdem ein sogenanntes Ächterprivileg, das es dem Grafen erlaubte, mit geächteten Personen zu verkehren und ihnen in seinen Herrschaften Schutz zu bieten - was er zweifellos nur tat, wenn er selber in erheblichem Mass davon profitieren konnte. Das Ächterprivileg dürfte in der Praxis kaum Bedeutung gehabt haben.

Die Verleihung dieser Privilegien war im Spätmittelalter keine Ausnahme, sondern ein „Massengeschäft“. Allein am 16. Oktober 1379 stellte König Wenzel fast 40 solcher Gerichtsstandsprivilegien aus. ${ }^{21}$ Die Privilegien bedeuteten in erster Linie eine Anerkennung und Stärkung der landesherrlichen Gerichtsbarkeit. In der Praxis zeigte sich - obwohl dieses Privileg immer wieder bestätigt wurde und ein Verstoss dagegen mit einer schweren Strafe („fünfzig Mark lötiges Gold“) bedroht war -, dass sich die Freiheit vor fremden Richtern nicht vollständig durchsetzen liess. Bis zu seiner Aufhebung im Jahr 1806 befasste sich das kaiserliche Landgericht in Rankweil immer wieder mit Fällen aus Liechtenstein. ${ }^{22}$.

Die Gerichtsbarkeit hatte nicht nur rechtliche, sondern auch wirtschaftliche und symbolische Bedeutung. Die Strafgelder und in bestimmten Fällen auch der Vermögenseinzug waren eine Einnahmequelle für die Landesherren, bei der niederen Gerichtsbarkeit waren auch die Landammänner daran beteiligt. Wichtiger war die symbolische Bedeutung: Der Landesherr sorgte für Frieden. Die Rechtspflege wurde zum Symbol der hoheitlichen, dem Landesherrn reichsrechtlich verliehenen Macht.

\section{Reichsunmittelbarkeit}

Reichsunmittelbarkeit bezeichnete den Status von Personen und Gütern, die unmittelbar dem König und Reich unterworfen waren und keinem Landesherrn unterstanden. Die Reichsunmittelbarkeit war ein Privileg, das vom Kaiser hochadeligen Personen und Städten für ihre treuen Dienste verliehen wurde. Voraussetzungen waren eine hochadelige Herkunft und die Belehnung mit einem Reichslehen. Beim Tod des Lehenträgers fiel das Reichslehen - sofern der Lehenträger das Treueverhältnis nicht gebrochen hatte - nicht an das Reich zurück, sondern ging an die Erben. Die reichsunmittelbaren Rechte konnten wie ein freies Eigen verkauft, getauscht, verpfändet oder vererbt werden. ${ }^{23}$ Dafür war die Einwilligung des Kaisers nicht notwendig.

Wann den Grafen von Werdenberg vom König erstmals die Reichsunmittelbarkeit verliehen wurde, ist eine offene Frage - möglicherweise gab es gar keine „Erstverleihung“: Man geht heute eher davon aus, dass die Grafen von Werdenberg nach dem Erlöschen des Herzogtums Schwaben weitgehende Herrschafts- und Hoheitsrechte ohne

21 Ich bedanke mich bei Stefan Frey für diese freundliche Mitteilung vom 4. April 2020.

22 Tiefenthaler, Rupert: Rankweil. In: Historisches Lexikon des Fürstentums Liechtenstein online (eHLFL), URL: https://historisches-lexikon.li/Rankweil, abgerufen am. 13.4.2020.

23 Scheidemantel, Heinrich Gottfried - Häberlin, Karl Friedrich: Repertorium des Teutschen Staats- und Lehnrechts. Bd. 3. Leipzig 1793, S. 37. 
Verleihung in Anspruch nahmen und daran nicht gehindert wurden. ${ }^{24}$ Die älteste erhaltene Bestätigung der Reichsunmittelbarkeit stammt aus dem Jahr 1396: König Wenzel bestätigte den Grafen Hartmann, Bischof von Chur, und dessen Bruder Heinrich die Grafschaft Vaduz und alle ihre übrigen Herrschaften als Reichslehen. ${ }^{25}$ Als Regalien wurden aufgeführt „Länder und Leute“ mit Städten, Festungen, Märkten, Gerichten, Zöllen, Mühlen, Äckern, Wiesen, Wäldern, Gebüschen, Gewässern, Teichen, Jagdgründen und Vogelweiden. Diese Rechte entsprachen wohl einem standardmässigen Katalog ohne Rücksicht auf die lokalen Verhältnisse, denn Städte und Märkte gab es in der damaligen Grafschaft keine. Die Verleihung erfolgte nicht nur an die beiden genannten Grafen persönlich, sondern auch an ihre Erben. Die Praxis, Reichslehen wie ein freies Eigen zu behandeln, wurde beim Verkauf an die Grafen von Sulz im Kaufvertrag von 1510 ausdrücklich erwähnt: Der Verkauf der Herrschaften erfolge „under dem tittel aigner fryer vnnd langhar gebrachter ruewiger herlichayt [und] gerechtigkait“ ${ }^{26}$ Die Gerichtsbarkeit wurde bei der Verleihung der Reichsunmittelbarkeit nur mit dem Wort „Gerichte“ erwähnt, ohne diese zu spezifizieren. Es kann aber kein Zweifel bestehen, dass die Grafen auch die Blutgerichtsbarkeit wahrnahmen, denn 1402 verglichen sich Graf Hartmann von Werdenberg-Sargans zu Vaduz und Graf Albrecht von Werdenberg der Ältere über die Ausübung der Blutgerichtsbarkeit am Eschnerberg beziehungsweise in der Herrschaft Schellenberg. ${ }^{27}$ Bischof Hartmann von Chur liess sich 1402 die Reichsunmittelbarkeit von König Ruprecht erneut bestätigen..$^{28}$

\section{Brandisische Freiheiten von 1430 und 1492}

1430 verlieh König Sigismund Freiherr Wolfhart von Brandis die „Brandisischen Freiheiten " für die Herrschaften Blumenegg, Vaduz und Schellenberg. In der Urkunde wurden die Gerichtsstandsprivilegien vom 16. Oktober 1379 bestätigt, wobei nun auch die Blutgerichtsbarkeit („ban vber das bluot zuo richten“) ausdrücklich erwähnt wurde..$^{29}$ Diese „Urfassung“ der Brandisischen Freiheiten beschränkte sich auf die Gerichtsbarkeit, im Zentrum stand die Freiheit vor fremden Gerichten. Die Regalien und nutzbaren Rechte, die den Landesherren vom König verliehen wurden, fanden keine Erwähnung. Bestätigt wurden auch die Strafbestimmungen von 1379, das Ächterprivileg hingegen fehlte.

In der Landesgeschichte gilt die Verleihung der Brandisischen Freiheiten durch König Sigismund im Jahr 1430 als Meilenstein auf dem Weg zur staatlichen Selbstständigkeit.

24 Dopsch, Heinz: Vaduz (Grafschaft). In: Historisches Lexikon des Fürstentums Liechtenstein (eHLFL), online: historisches-lexikon.li/Vaduz_(Grafschaft).

25 Prag, 22. Juli 1396. LUB I, Bd. 2, Nr. 80.; online: www.e-archiv.li/D47441.

26 Verkaufsurkunde vom 14. Juli 1510, Österreichisches Staatsarchiv, Haus-, Hof- und Hausarchiv Wien, AUR 1510 Juli 12; online: www.e-archiv.li/D45743.

27 Urkunde vom 30. November 1402, LUB I, Bd. 3, Nr. 114.; online: www.e-archiv.li/D46907.

28 Kaiser, P.: Geschichte, S. 200.

29 Urkunde vom 26. Dezember 1430, Liechtensteinisches Landesarchiv Vaduz (weiter LI LA), Schä U 9; online: www.e-archiv.li/D44622. 


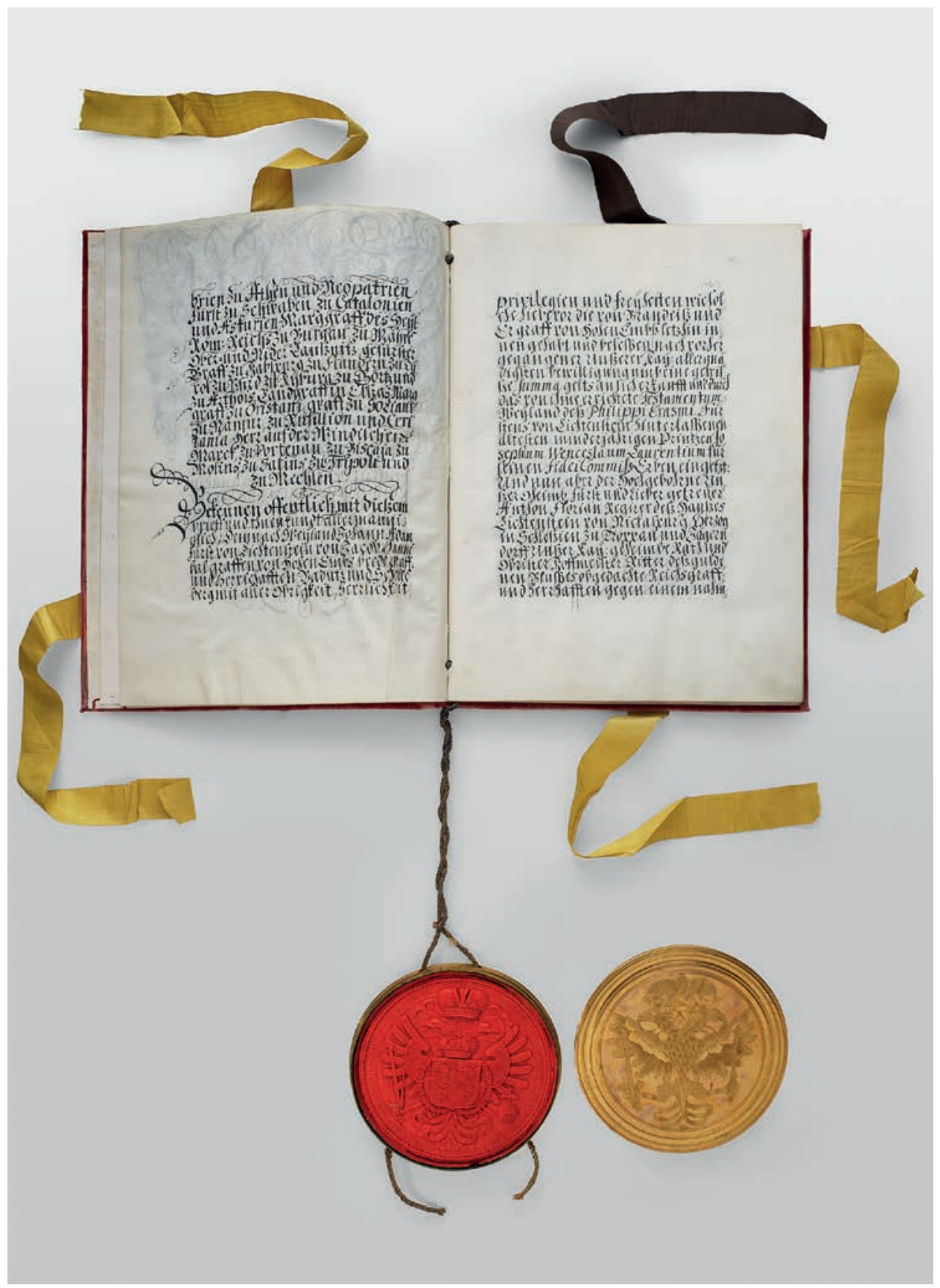

Kaiser Karl VI. bestätigt am 23. Februar 1719 dem Fürsten Anton Florian die Brandisischen Freiheiten vom 26. Dezember 1430. (Original: Hausarchiv Liechtenstein, Wien; Foto: LIECHTENSTEIN. The Princely Collections. Inv. Nr. UR 1719.01.23.2.) 
Dabei wird gern übersehen, dass 1492 die Privilegien wesentlich erweitert wurden: ${ }^{30}$ Neu wurden auch die Bergwerke, Zölle, Mauten, Steinbrüche und Gewässer unter den Reichslehen aufgeführt. Eine Stärkung der landesherrlichen Rechte bedeutete die besondere Erwähnung der „Gerichtszwänge“ (Kompetenz, Recht zu sprechen und Urteile durchzusetzen) und von „Twing und Bann" (Gebots- und Verbotsgewalt im dörflichen Bereich). Die Grafen konnten die Gerichtsbarkeit delegieren, was Möglichkeiten für die Beteiligung der Landschaften und Dorfgemeinschaften eröffnete. Die Möglichkeit, auch die hohe Gerichtsbarkeit an geeignete Personen zu übertragen (also an Beamte oder Ammänner) wurde erstmals ausdrücklich erwähnt. Die Richter hatten das Recht, Beschuldigte peinlich zu befragen und nach den Reichsgesetzen zu bestrafen. Alle Leute, die in den Herrschaften der Brandis wohnten, mussten diese als ihre Herren und Richter anerkennen. Fremde, die sich in den Herrschaften niederliessen, mussten den Landesherren huldigen und Gehorsam schwören. Das Ächterprivileg wurde wieder aufgenommen.

Der Begriff „Brandisische Freiheiten“ stammt nicht aus der Zeit. Erstmals verwendet wurde er 1614, als Kaiser Mathias Graf Kaspar von Hohenems die Privilegien bestätigte. ${ }^{31}$ Die Urkunde von 1492 enthält eine Abänderung in Bezug auf die Freiheit vor fremden Gerichten: Diese wurde in Bezug auf das kaiserliche Hofgericht in Rottweil eingeschränkt, die Bedeutung des Hofgerichts wurde aufgewertet.

Die Bedeutung, die man den Brandisischen Freiheiten zumass, geht daraus hervor, dass sie bis 1719 über 25mal bestätigt wurden. Zusätzlich wurde die Blutgerichtsbarkeit allein noch einmal fünfmal bestätigt, ohne dass sich daraus ein Mehrwert ergeben hätte. ${ }^{32}$ Bei einer Bestätigung wurde jeweils eine neue Urkunde ausgestellt, wobei im Anfangs- und Schlussteil der Aussteller genannt wurde, der als Gewährsmann auftrat. Der Text der Urkunde von 1492 wurde jeweils wörtlich in die neue Urkunde inseriert.

\section{Rechtsetzung, Steuererhebung, Truppenaufgebot}

Neben der Blutgerichtsbarkeit und den Regalien waren die Rechtssetzung, die Steuerhoheit und das Truppenaufgebot die wichtigsten Hoheitsrechte der Landesherren. $\mathrm{Zu}$ erwähnen sind weiter die Religionshoheit und die Bewilligung der Ein- und Auswanderung. Die grundherrlichen Rechte (Fronen, Zehnten etc.) fallen nicht unter die hoheitlichen Rechte, da sie auch von Klöstern und andern Personen erworben werden konnten.

Neues Recht wurde nur erlassen, wenn beim alten Recht Missbräuche oder Unsicherheiten festgestellt wurden, die immer wieder zu Konflikten und Rechtsstreitigkeiten führten. Von einer Gesetzgebung im modernen Sinn, bei der alle hoheitlichen Belange im Interesse des Rechtsstaats geregelt werden, kann noch nicht gesprochen werden. $\mathrm{Zu}$ berücksichtigen ist allerdings die magere Quellenlage: Viele Texte, so auch historische

30 Urkunde vom 16. Oktober 1492, LI LA U 44 Insert; online: www.e-archiv.li/D44278.

31 Ritter, Rupert: Die Brandisischen Freiheiten. Jahrbuch des Historischen Vereins für das Fürstentum Liechtenstein 43, 1943, S. 5-42, hier S. 9.

32 Eine unvollständige Zusammenstellung der Bestätigungen Ritter, R.: Die Brandisischen Freiheiten, S. 5-42. 
Rechtsquellen, gingen verloren. Zu hinterfragen ist auch, inwieweit Recht überhaupt verschriftlicht wurde oder ob das angewandte Recht nicht viel mehr auf Gewohnheitsrecht und auf Reichsrecht beruhte. Die meisten neuen Ordnungen, die seit dem 16. Jahrhundert erlassen wurden, betreffen die Wälder, deren Nutzung immer wieder zu Konflikten führte. Erwähnenswert ist die neue Ordnung betreffend Erbfolge, Testamente und Verjährung von $1531 .{ }^{33}$ Der Landsbrauch, von dem wesentliche Teile ebenfalls aus dem 16. Jahrhundert stammen, war eine Sammlung von Rechtsvorschriften, in der das Erbrecht, das Schuld- und Pfandrecht, das Malefizgericht (Blutgericht) und eine Polizeiordnung enthalten waren. Bei der Entstehung dieser Ordnungen überlagerten sich Einflüsse des alten Gewohnheitsrechts und der Reichsgesetzgebung. Ähnliches gilt für die „Landsöffnung“, die bei der „Amtsbesetzung“ (Landammannwahl) den Untertanen vorgelesen und von diesen beschworen wurde. Sie enthielt eine Reihe von Vorschriften zur "guten Poli$z e i$ “. Die älteste Abschrift stammt aus dem Jahr 1614 und zeigt bereits deutlich absolutistische Züge: Graf Kaspar von Hohenems bezeichnet sich darin als „von Gott geordnete und vorgesetzte Obrigkeit" - ein Verweis auf seine reichsrechtlich begründete Stellung fehlte.

Schufen die Landesherren wenigstens in Teilbereichen neues, „besseres “ Recht, so konnten sie die Steuerhoheit nie durchsetzen, konkret die Steuern nicht erhöhen. Seit dem Mittelalter gibt es Hinweise auf Steuern, die von verschiedenen Herren bezogen wurden. Den Freiherren von Brandis gelang es bis 1437, diese Steuern in ihrer Hand zu vereinen. Der Einzug der Steuern oblag den Landschaften, wobei nicht der einzelne Steuergenosse, sondern die Steuergenossenschaft als Ganze dem Landesherrn die Steuer schuldete. Wie die Steuer umgelegt und eingezogen wurde, regelte die Genossenschaft selber; der Landesherr sollte sich nicht einmischen. Die „Landsteuer" war eine jährliche, moderate Steuer, die in der Höhe nicht variierte (89 Pfund Pfennig für die Grafschaft Vaduz und 77 Pfund Pfennig für die Herrschaft Schellenberg) und nicht der Bewilligung durch die Landschaften unterlag. Vom 15. Jahrhundert bis ins frühe 19. Jahrhundert wurde sie nie erhöht. Neben der Landsteuer gab es die Reichssteuer, den sogenannten „Schnitz“. Der Schnitz war ursprünglich eine ausserordentliche Steuer, die zur Bezahlung der Reichslasten erhoben wurde. Die Modalitäten wurden 1584 zwischen Karl Ludwig von Sulz und den beiden Landschaften vereinbart. 1614 schloss Kaspar von Hohenems mit den beiden Landschaften Steuerverträge: Er verpflichtete sich, die gesamten Reichs- und Kreislasten zu übernehmen, wofür ihm die Untertanen der Grafschaft Vaduz 860 und jene der Herrschaft Schellenberg 416 Gulden entrichten mussten. Für die Untertanen erwiesen sich diese Verträge als sehr vorteilhaft, da die Reichs- und Kreislasten anstiegen, die Steuerhöhe aber fixiert war. Dank der Geldentwertung wurde die steuerliche Belastung für die Untertanen weniger drückend. Gegen Vertragsänderungen wehrten sie sich erfolgreich, was einer der Hauptgründe für die massive Verschuldung der Grafen von Hohenems war. Der Vertrag wurde durch die kaiserliche Administrationskommission 1696 aufgehoben. Die Untertanen mussten darauf sämtliche Reichs- und Kreislasten übernehmen.

33 Ordnung betr. Erbfolge, Testamente und Verjährung vom 24. August 1531, LI LA Schä U 53.; online: www.e-archiv.li/D48477. 
Neben Gerichtsbarkeit, Gesetzgebung und Steuerhoheit bildete die Truppenstellung einen weiteren Schwerpunkt der Landeshoheit. Seit dem 15. Jahrhundert stellten die Landschaften Vaduz und Eschnerberg je eine „Miliz“ (Landwehr) zur Landesverteidigung. Alle männlichen Untertanen ab 16 Jahren mussten sich mit Waffen ausrüsten. Die Bedeutung dieser bäuerlichen Miliz lag eher in der Symbolik als in ihrem militärischen Nutzen. Bei den Landammannwahlen und wohl auch bei Huldigungen traten die Untertanen in militärischen Formationen an, sie übernahmen Ordnungsdienste und leisteten einen Treueeid. ${ }^{34}$ Neben dieser Miliz gab es noch ein kleines Kreiskontingent (acht Mann in Kriegszeiten und fünf in Friedenszeiten), das seit der Schaffung des Schwäbischen Kreises unterhalten werden musste ${ }^{35}$ - eine Verpflichtung, die man mehr schlecht als recht erfüllte.

\section{Fixierung der Landes- und Herrschaftsgrenzen}

Eine der Voraussetzungen für einen Territorialstaat waren feste, eindeutige Grenzen des Territoriums. Die schriftlichen Quellen zur Festlegung von Herrschaftsgrenzen reichen in die zweite Hälfe des 14. Jahrhunderts zurück. Die letzte wichtige Grenzänderung erfolgte 1515, als in einem Grenzvertrag mit Kaiser Maximilian die Nordgrenze der Herrschaft Schellenberg festgelegt wurde. ${ }^{36}$

In der Regel entstanden Grenzstreitigkeiten aufgrund von Nutzungskonflikten - es ging um Fragen wie: wer wo sein Vieh weiden und tränken durfte, wer wo Holz schlagen oder jagen durfte, wer wo Wuhren (Dämme am Rhein) erstellen durfte. Nur ausnahmsweise ging es um landesherrliche Rechte wie Zoll, Strassenmaut, Zehnten oder den Besitz von Leibeigenen.

In den Nutzungsstreitigkeiten traten in der Regel nicht die Landesherren als Streitparteien auf, sondern die Gemeinden. Herrschaftsübergreifende Streitigkeiten wurden häufig durch ein Schiedsgericht geregelt, das vom Landesherrn unabhängig war. Im Spruch der Richter wurde der Grenzverlauf beschrieben, anschliessend wurden Grenzsteine gesetzt oder Grenzmarken bestimmt (z.B. auffallende Besonderheiten im Gelände). Der Grenzverlauf wurde auch in den Urbaren der beiden Herschaften ${ }^{37}$ beschrieben, womit die Grenzbeschreibungen (zumindest aus Vaduzer Sicht) einen verbindlichen Charakter erhielten. Seit 1510 wurden diese Grenzen nur noch geringfügig verändert; 1719 wurden sie zu den Landesgrenzen des Fürstentums Liechtenstein.

34 Frommelt, Fabian - Quaderer Rupert: Militär. In: Historisches Lexikon des Fürstentums Liechtenstein, online (eHLFL), http://historisches-lexikon.li/Militär.

35 Kaiser, P.: Geschichte, S. 463.

36 Erwähnt in: Sulzisch-hohenemsisches Urbar der Grafschaft Vaduz von 1614, HAL Wien, Hs. 7, S. 1-131, online: www.e-archiv.li/D48445.

37 Urbar der Herrschaft Schellenberg, Abschrift von 1699, HAL Wien, U 1699; online: www.e-archiv.li/ D42836. Sulzisch-hohenemsisches Urbar der Grafschaft Vaduz um 1614, HAL Wien, Hs. 7, S. 1-131, online:: www.e-archiv.li/D48445. 


\section{Die Reichsstandschaft - Verankerung im Reich}

\section{Nähe zu Habsburg}

Bis zum Schwaben- oder Schweizerkrieg (1499) stiessen die Eidgenossen und das aufstrebende Habsburg-Österreich im Rheintal wiederholt militärisch aufeinander, da beide eine expansive Erwerbspolitik betrieben. Den Habsburgern gelang es, zwischen 1363 und 1523 fast sämtliche Herrschaften im heutigen Vorarlberg zu erwerben. Westlich des Rheins brachten sie 1396 vorübergehend die Grafschaft Sargans als Pfand in ihren Besitz. Die Eidgenossen ihrerseits sicherten sich die Herrschaften links des Rheins (heute Kanton St. Gallen). Die Grafschaft Vaduz und die Herrschaft Schellenberg lagen mitten im Spannungsfeld der beiden Parteien.

Die Landesherren von Vaduz waren in der Regel loyale Gefolgsleute der Habsburger, denen sie weitgehend ausgeliefert waren. Sie versuchten aber auch, mit den Eidgenossen gute Beziehungen zu unterhalten (z.B. durch den Erwerb des Burgrechts in Bern). Letztlich konnten sie sich nicht aus den Kriegen heraushalten. Sowohl im Alten Zürichkrieg (1439-1446) wie auch im Schwabenkrieg (1499) nahmen sie Partei für Österreich und mussten dafür bitter büssen. Die Kriege führten dazu, dass das Land und die Landesherren verarmten.

Obwohl die Eidgenossen militärisch recht erfolgreich kämpften, verzichteten sie 1499 im Frieden von Basel auf grosse territoriale Gewinne. Wichtigstes Ergebnis war, dass der Rhein zu einer anerkannten, dauerhaften festen Grenze wurde. Die territorialen Konflikte zwischen Österreich und der Eidgenossenschaft waren für die Zukunft geklärt. ${ }^{38}$ Die künftigen Beziehungen zwischen den beiden waren friedlich, wenn auch nicht konfliktfrei. Die Eidgenossen scheinen schlicht kein Interesse an einer dauerhaften Eroberung von Vaduz und Schellenberg gehabt zu haben. 1499 besetzten sie die beiden Herrschaften, die Untertanen mussten ihnen einen Treueeid schwören. Nach dem Friedensschluss gaben sie die beiden Herrschaften an die Brandis zurück, nun mussten die Untertanen wieder ihren alten Landesherren huldigen. ${ }^{39}$

Warum aber waren die Habsburger nur mässig an einem Erwerb der beiden Herrschaften interessiert, die doch eine Arrondierung ihres Besitzes ermöglicht hätten? Da ist zunächst darauf zu verweisen, dass alle Dynastien in Vaduz kaisertreu und katholisch waren. Die kleinen Herren stärkten und stabilisierten das Königtum. Umgekehrt schützte und stärkte dieses die kleinen Landesherren mit zahlreichen Privilegien. Für den Kaiser entstand kein Nutzen, wenn er treue Gefolgsleute eliminierte, die von ihm abhängig waren. Letztlich profitierten beide Seiten: Für die kleinen Landesherren waren kaiserliche Dienste sehr attraktiv, da sie mit bedeutenden Einkünften, einer vornehmen Stellung und Prestigegewinn rechnen konnten. Oft reichten die Einnahmen aus den

38 Dies gilt noch nicht für den Grenzverlauf zum heutigen Kanton Graubünden, der damals noch nicht zur Eidgenossenschaft gehörte. Claudius, Gurt: Schwabenkrieg, In: Historisches Lexikon des Fürstentums Liechtenstein, online (eHLFL): https://historisches-lexikon.li/Schwabenkrieg.

39 Gurt, Claudius: Schwabenkrieg. In: https://historisches-lexikon.li/Schwabenkrieg. Genommen am 8. 10. 2020. 
Herrschaften für den Unterhalt der Familie nicht aus, so dass sie auf zusätzliche Einkünfte angewiesen waren.

Militärisch war ein Erwerb der beiden Herrschaften Vaduz und Schellenberg aus Sicht der Habsburger nicht notwendig. Die Landesherren in Vaduz waren zu einer engen Kooperation bereit und liessen sich in das Vorarlberger Landesverteidigungssystem einbinden. 1505, also kurz nach dem Schwabenkrieg, schlossen König Maximilian und Ludwig von Brandis einen „ewigen Schutz- und Schirmvertrag“, der auch als „Schlossöffnungsvertrag" bekannt wurde. Darin verpflichtete sich Ludwig von Brandis gegen ein jährliches Entgelt von 200 Gulden dem König die Burg Vaduz jederzeit offen zu halten. Die beiden vereinbarten, einander im Kriegen oder bei Aufruhr zu helfen. Österreich wurde zugestanden, die Burg Vaduz jederzeit zu besetzen. Um das Risiko zu eliminieren, dass Habsburg durch diesen Vertrag ungewollt in einen Krieg hineingezogen wurde, mussten sich die Brandis verpflichten, ohne Wissen der Habsburger oder deren Amtsleute mit niemandem „Händel“ anzufangen. ${ }^{40}$ Spätestens ab 1505 waren Vaduz und Schellenberg in das Verteidigungssystem der „Vorarlberger Landesrettung“ einbezogen, das hauptsächlich zur Alarmierung und Aufbietung der Miliz im Falle einer Kriegsgefahr errichtet wurde. ${ }^{41}$ Ein entsprechendes Abkommen wurde 1531 und 1603 erneuert. ${ }^{42}$

1517 unterstützte Kaiser Maximilian den Wiederaufbau der Burg Vaduz mit 2000 Gulden. Dafür musste Rudolf von Sulz dem Haus Habsburg ein Vorkaufsrecht auf die beiden Herrschaften einräumen. Weiter musste er sich verpflichten, keinen Vertrag abzuschliessen, der gegen den Schlossöffnungsvertrag von 1505 verstiess. ${ }^{43} 1523$ erhielt Rudolf von Sulz noch einmal 1200 Gulden, die für den militärischen Ausbau der Burg Vaduz und der Küssaburg zu verwenden waren. ${ }^{44}$

Das Fehlen von grossen militärischen Vorteilen und die angespannte finanzielle Situation der Habsburger erklären, warum diese nicht entschiedener versuchten, die beiden Herrschaften in ihren Besitz zu bringen. Bei den Herrschaftswechseln traten sie nie als ernsthafte Konkurrenten der Käufer auf. Dokumentiert sind lediglich zwei Versuche zur Übernahme der Herrschaften: Da Sigmund von Brandis und sein Bruder Ludwig keine männlichen Nachkommen hatten, verhandelte Sigmund von Brandis 1504 mit König Maximilian über einen Verkauf. Er erhielt auch bereits 1100 Gulden, die bei einem Verkauf mit der Kaufsumme verrechnet werden sollten. 1506 sicherte der Brandis dem König ein Vorkaufsrecht zu. ${ }^{45}$ Ludwig und Sigmund von Brandis verstarben beide im Jahre 1507. Johannes von Brandis, Dompropst in Chur und letzter Freiherr von Brandis, verkaufte dann aber nicht an König Maximilian, sondern an seinen Neffen Rudolf V.

40 Schlossöffnungsvertrag vom 2. Mai 1505; LI LA U 85; online: www.e-archiv.li/D44281, Seger, O.: Herrschaftsübergang, S. $30 \mathrm{ff}$.

41 Kaiser, P.: Geschichte, S. 328.

42 Niederstätter, Alois: Vorarlberger Landesrettung. In: Historisches Lexikon des Fürstentums Liechtenstein, online (eHLFL): historisches-lexikon.li/Vorarlberger_Landesrettung.

43 Seger, O.: Herrschaftsübergang, S. 41.

44 Seger, O.: Herrschaftsübergang, S. 42.

45 Stievermann, Dieter: Brandis, Sigmund II. von. In: Historisches Lexikon des Fürstentums Liechtenstein, online historisches-lexikon.li/Brandis,_Sigmund_II._von, abgerufen am 15.4.2020. 
von Sulz. Kaiser Maximilian, der offenbar fest damit gerechnet hatte, dass die beiden reichsunmittelbaren Herrschaften nach dem Tod des letzten Brandis an das Reich heimfallen würden, soll über diesen Verkauf sehr verstimmt gewesen sein. ${ }^{46}$

Das zweite Mal zeigte sich Habsburg-Österreich in den Jahren 1608/09 an einem Kauf interessiert, als die hoch verschuldeten Grafen von Sulz verkaufen mussten. Diesmal verhinderten die Vorarlberger Landstände einen Kauf, da sie für sich keinen Vorteil sahen und befürchteten, für den Kaufpreis aufkommen zu müssen. Sie bezweifelten auch den militärischen Sinn eines solchen Kaufs, da die sulzischen Herrschaften einen Puffer zwischen Österreich und der Eidgenossenschaft darstellten. Schliesslich sahen die Habsburger von einem Kauf ab und wären sogar bereit gewesen, dem Abt von St. Gallen den Vortritt zu lassen. ${ }^{47}$

\section{Reichsstandschaft und Reichsreformen um 1500}

In der liechtensteinischen Geschichtsschreibung wird die Bedeutung der Reichsunmittelbarkeit stark betont, während die Reichsstandschaft erst im Zusammenhang mit der Erhebung zum Reichsfürstentum thematisiert wird. Die Bedeutung der Reichsstandschaft war aber den Zeitgenossen bewusst, denn im Urbar von 1614 wurde ausdrücklich darauf hingewiesen, dass der Besitzer der Reichsgrafschaft Vaduz ein Reichsstand, der Blutbann ein Reichslehen und alles Übrige freies Eigentum seien. ${ }^{48}$

Der Wormser Reichstag von 1495 wurde von König Maximilian I. einberufen, weil die Reichsstände eine finanzielle Unterstützung für seinen Italienzug und die Türkenbekämpfung beschliessen sollten. Die Reichsstände verweigerten diese nicht, machten sie jedoch von erweiterten Mitwirkungsrechten abhängig. Schliesslich dominierten am Reichstag nicht die aussenpolitischen Themen, sondern die innenpolitischen: Hauptanliegen war die Sicherung des Friedens durch Stärkung des Rechts. Fehden wurden verboten. Aufgabe des neu geschaffenen Reichkammergerichts war es, Konflikte zwischen den Reichsständen wie auch zwischen den Landesherren und ihren Untertanen durch ein ordentliches Gerichtsverfahren zu lösen. Das Reichskammergericht wurde durch Beiträge der Reichsstände finanziert und bekam damit eine gewisse Unabhängigkeit vom König bzw. Kaiser. 1498 wurde mit dem Reichshofrat ein zweites oberstes Reichsgericht eingerichtet, das stärker unter dem Einfluss des Kaisers stand. Der Reichshofrat arbeitete weniger juristisch, sondern suchte oft mit Hilfe von Kommissionen, die direkt vor Ort arbeiteten, nach politischen oder pragmatischen Lösungen. Für das Gebiet des späteren Fürstentums Liechtenstein wurde vor allem der Reichshofrat von Bedeutung, da der Kaiser zwischen 1680 und 1725 von den Untertanen in zwei Konflikten mit dem

46 Stievermann, D.: Brandis, Sigmund II. von. In: HLFL, online historisches-lexikon.li/Brandis,_Sigmund_ II._von, abgerufen am 15.4.2020; Seger, O.: Herrschaftsübergang, S. 35.

47 Seger, O.: Herrschaftsübergang, S. 65.

48 Urbar von 1614: Der Besitzer der Reichsgrafschaft ist „ein stand deß Reichs und sovil den bluetpann und berckhwerckh betrifft, ein lehen vom Römischen Reich, das uberig und anders ein frey aigenthumb.“ HAL Wien, Hs. 7, S. 1-131, online: www.e-archiv.li/D48445. 
Landesherr angerufen wurde und der Reichshofrat mit einer Konfliktlösung beauftragt wurde.

Mit den Reichstagsbeschlüssen von 1495 wurde der Reichstag massiv aufgewertet: Er wurde zu einem Verfassungsorgan, die Reichsstände erhielten einen Anspruch auf eine institutionalisierte Mitwirkung in der Reichspolitik und vor allem erhielten sie das Recht, Reichssteuern zu bewilligen. Die Reichsgewalt wurde im Sinne des Dualismus zwischen König und Reichsständen geteilt. Wichtige Entscheidungskompetenzen gingen vom Kaiser auf die Landesherren über. Um Entscheide in seinem Sinne zu bekommen, musste sich der Kaiser auf Verhandlungen mit den Reichsständen einlassen, was nicht nur die grossen Landesherren stärkte.

Die kleinen Landesherren waren oft nicht in der Lage, persönlich an den Reichstagen teilzunehmen, meist liessen sie sich vertreten. Sie hatten nicht wie die Fürsten eine Virilstimme (eine eigene Stimme), sondern nur eine Kuriatstimme (Kollektivstimme) - zusammen mit andern Prälaten oder Grafen aus dem gleichen Reichskreis. Das politische Gewicht der einzelnen Grafen war gering, die Reichsstandschaft war trotzdem ein lohnendes Ziel. Von daher war es gerade um 1500, als die Reichsmatrikel (Verzeichnis der Reichsstände und ihrer Pflichten) angelegt wurden, an den Reichstagen Präsenz zu markieren, um so auf sich und ihre Rechte hinzuweisen. Die Belege, dass die Freiherren von Brandis an den Reichstagen teilnahmen, sind nicht zahlreich, aber sie sind vorhanden. Besonders aktiv war Ortlieb von Brandis, der in seiner Funktion als Fürstbischof von Chur auch Reichsfürst war und schon von daher teilnahmeberechtigt war. Der umtriebige Bischof beschränkte seine Tätigkeiten nicht auf sein Kirchenamt, sondern trat auch als Landesherr seiner Herrschaften Vaduz, Schellenberg, Blumenegg und Maienfeld auf. Er nahm mehrmals an Reichstagen teil und pflegte gute Beziehungen zu Kaiser Friedrich III., für den er mehrfach als kaiserlicher Gesandter tätig war. ${ }^{49}$ Ortlieb starb 1491, konnte also am Wormser Reichstag nicht mehr teilnehmen. Dass Kaiser Friedrich III. auch seinen Nachfolgern wohl gesinnt war, geht daraus hervor, dass er 1492 den Brüdern Ludwig und Sigmund von Brandis (zwei Neffen des Bischofs) die Brandisischen Freiheiten nicht nur bestätigte , sondern beträchtlich erweiterte, ${ }^{50}$ zudem verlieh er ihnen die Rotwachsfreiheit. ${ }^{51} \mathrm{Ob}$ am Wormser Reichstag von 1495 ein Freiherr von Brandis teilnahm, ist nicht bekannt - ausgeschlossen ist es nicht, da Maximilian I. kurz darauf (1496) den Brüdern Ludwig und Sigmund von Brandis ihre Privilegien erneut bestätigte..$^{52}$

49 Mayer, Johann Georg: Ortlieb von Brandis, Bischof von Chur. Jahrbuch des Historischen Vereins für das Fürstentum Liechtenstein 4, 1904, S. $140 \mathrm{f}$.

50 Urkunde vom 16. Oktober 1492, Regest in:LUB, 2. Teil. Online: http://www.lub.li/detail.aspx?Certid=1182\&backurl=yearinfo.aspx?Year=1492.

51 Urkunde vom 24. Oktober 1492, Regest in: LUB, 2. Teil. Online: http://www.lub.li/decaderegister. aspx?LubYear=1500\&\&lftColBl5=??, aufgerufen am 21.3.2020.

52 Urkunde vom 16. September 1496, Regest in: LUB, 2. Teil, online: http://www.lub.li/decaderegister. aspx?LubYear=1500\&\&lftColBl5=?? 
Am Reichstag in Konstanz von 1507 nahm Sigmund II. von Brandis teil. ${ }^{53}$ Erneut liess er sich von Maximilian I. die Brandisischen Freiheiten bestätigen. Wichtiger war aber, dass Brandis in die Reichsmatrikel von 1507 aufgenommen und damit als Reichsstand anerkannt wurde. Brandis verpflichtete sich, entsprechende Reichslasten zu übernehmen: An den Kosten des Reichskammergerichts musste er sich mit 12 Gulden, am Reichsregiment mit 2 Mann und 80 Gulden beteiligen. ${ }^{54}$

Das Recht auf die Reichsstandschaft ergab sich nicht automatisch aus der Reichsunmittelbarkeit - nicht allen reichsunmittelbaren Herrschaften wurde diese zugestanden. Ursprünglich konnte der Kaiser die Reichsstandschaft auch an Personen verleihen, die über kein reichsunmittelbares Territorium verfügten (sog. Personalisten), doch erschwerten die Reichsstände im 17. Jahrhundert die Erlangung dieses Rechts zunehmend. Ein reichsunmittelbarer Besitz, alter Adel, die Aufnahme in die Reichsmatrikel und die Zustimmung des Kaisers waren unabdingbare Voraussetzungen. Ab 1654 wurde für die Aufnahme in den Reichstag mit „Sitz und Stimme“ auch die Zustimmung des Reichstags verlangt.

War eine Herrschaft in den Reichsmatrikeln eingetragen, so blieb sie offenbar drin, auch wenn sich die Herrschaftsverhältnisse änderten. In den Reichsmatrikeln seit 1521 wurde die Reichsstandschaft der Brandis (obwohl ausgestorben) bei derjenigen von Sulz bzw. später von Hohenems weiter erwähnt. ${ }^{55}$ Auch in Zedlers Universal-Lexikon aus der Mitte des 18. Jahrhunderts taucht die Reichsstandschaft der Brandis und die daraus erwachsenden Verpflichtungen bei den späteren Landesherren immer noch auf. ${ }^{56}$ Der Zweck der Reichsmatrikel bestand ja nicht darin, ein aktuelles Verzeichnis der Länder zu erstellen, sondern die finanziellen Verpflichtungen der Reichsstände festzuhalten.

Wie andere Grafen nahmen die Grafen von Hohenems nicht selber an Reichstagssitzungen teil - sie liessen sich höchstens vertreten, aber auch dies kam offenbar nur selten vor. ${ }^{57}$ Die Reichsstandschaft der Grafschaft Vaduz scheint über 200 Jahre lang (abgesehen von den zu erbringenden Reichslasten) mehr oder weniger nur auf dem Papier bestanden zu haben.

53 Stievermann, D.: Brandis, Sigmund II. von. In: HLFL, online: https://historisches-lexikon.li/Brandis,_Sigmund_II._von, abgerufen am 22. 3. 2020.

54 Deutsche Reichstagsakten, Der Reichstag zu Konstanz 1507, Reichsanschlag zur Finanzierung des Reichskammergerichts; online: http://reichstagsakten.de/index.php?vol=rta1507\&doc=dok272\&serie $=$ rv\&hlstr $=$ Brandis $\#$ hl1 und http://reichstagsakten.de/index.php?vol=rta1507\&doc=dok271\&serie=rv\&hlstr=Brandis\#hl1 | tab-panel-center-5 | | toc_ovw_head $\mid$.

55 Reichsmatrikel von 1521, online: https://de.wikisource.org/wiki/Reichsmatrikel_von_1521.

56 Stichwort Reichs-Matrickel, Zedler, Johan Jakob: Grosses vollständiges Universal-Lexicon Aller Wissenschafften und Künste. 64 Bde. Halle - Leipzig 1731- 754, hier Bd. 31, S. 131 und 133.

57 In der Liste der Vertreter des Standes Hohenems beim Reichstag und den Kreistagen tauchen nur zwei Vertreter von Hohenems an Reichstagen auf. Scheffknecht, W.: Kleinterritorium, S. 427-462. 


\section{Der Schwäbische Reichskreis}

Die Schaffung der Reichskreise, ${ }^{58}$ die 1500 am Reichstag in Augsburg beschlossen wurde, gehörte zu den einschneidenden Reichsreformen. Sie dienten vor allem der Durchsetzung des Rechts und der Friedenssicherung: Die wichtigsten Aufgaben waren die Aufstellung und der Unterhalt des Reichsheers, die Exekution der Reichsgerichtsurteile und die Verteilung der Reichssteuern. Weitere Aufgaben hatten sie im Bereich der Wirtschaft, des Polizei- und Wohlfahrtswesens. ${ }^{59}$ Vaduz, Schellenberg und Blumenegg wurden dem Schwäbischen Reichskreis zugeteilt, ebenso die Landgrafschaft Klettgau und die Reichsgrafschaft Hohenems. Die Grafen von Hohenems wurden erst 1602 in das Schwäbische Grafenkollegium aufgenommen. ${ }^{60}$ Sie versuchten, aufgrund der brandisisch-sulzischen Vergangenheit Anspruch auf zwei Sitze im Kreistag geltend zu machen, doch kamen sie damit nicht durch. ${ }^{61}$

Die Kreisstandschaft war an den Besitz eines reichsunmittelbaren Besitzes gebunden. Die Landesherren in Vaduz liessen sich an den Kreistagen (oft durch landesherrliche Beamte) vertreten. Die Grafen von Hohenems schickten von 1609 bis 1801 etwa an drei Viertel der Kreistage einen Vertreter. ${ }^{62}$ Die Präsenz der Fürsten von Liechtenstein war etwas schlechter: Sie beschickten im 18. Jahrhundert etwa zwei Drittel der Kreistage. ${ }^{63}$

Der Schwäbische Kreis war gerade für die kleinen Territorien eine Art Rückversicherung: Die kleinen Stände hatten wesentliche staatliche Defizite, sie wären gar nicht in der Lage gewesen, allen ihren Aufgaben selber nachzukommen. Scheffknecht spricht in diesem Zusammenhang von „ergänzender Staatlichkeit“. ${ }^{64}$ Er betont aber auch, dass die Landesherren ihre Landeshoheit nicht an den Kreis abgaben, insbesondere entwickelte sich keine Kreisgerichtsbarkeit, die neben oder gar über der landesherrlichen Gerichtsbarkeit gestanden hätte. ${ }^{65}$ Der Kreis und die Reichsordnung garantierten den Landesherrn nicht nur Schutz und Sicherheit im Kriegsfall, sondern auch bei Rebellion und Ungehorsam der eigenen Untertanen. Unzufriedene Untertanen wurden auf den Rechtsweg verwiesen. Wenn sie statt dem Rechtsweg Aufruhr und Widerstand vorzogen, konnten sie als Rebellen behandelt und scharf bestraft werden. ${ }^{66}$ Die Kreistruppen standen zur Unterstützung der Obrigkeit bereit. Im Fall von Liechtenstein wurde den

58 Ursprünglich gab es nur sechs, später zehn Kreise.

59 Schulz, Thomas: Liechtenstein im Schwäbischen Kreis. In: Liechtenstein - fürstliches Haus und staatliche Ordnung. Hg. von Volker Press. Vaduz 1987, S. 311-328.

60 Scheffknecht, W.: Kleinterritorium, S. 200.

61 Scheffknecht, W.: Kleinterritorium, S. 186.

62 Scheffknecht, W.: Kleinterritorium, S. 225.

63 Zahlen betreffend die Teilnahme liegen für die Jahre 1707 bis 1806 vor: Ein Drittel der Kreistage wurde nicht beschickt. Angaben nach: Schulz, T.: Liechtenstein, S. 327.

64 Scheffknecht, W.: Kleinterritorium, S. 171.

65 Scheffknecht, W.: Kleinterritorium, S. 171.

66 Ausführlicher dazu: Vogt, Paul: „Wann ein pauer zehen mahl recht hat, darf man ihm gleichwohl nicht recht lassen". Absolutistische Reformen und Widerstand (1719-1733). In: Jahrbuch des Historischen Vereins für das Fürstentum Liechtenstein 118, 2019, S, 93-132. 
rebellierenden nach der Erhebung zum Reichsfürstentum Liechtenstein wiederholt gedroht, die Truppen des Schwäbischen Kreises zu Hilfe zu rufen - doch blieb es bei Drohungen. Ein solches Eingreifen hätte zu einem enormen Prestigeverlust der Liechtenstein geführt.

\section{Westfälischer Frieden}

Der Dreissigjährige Krieg endete 1648 mit dem Westfälischen Frieden. Mit dem Friedensvertrag wurde die Landeshoheit der Territorialherren gefestigt, die Balance zwischen Kaiser und Reichsständen neu austariert und zugunsten der letzteren verschoben. Die Reichsstände mussten sich an die Beschlüsse von Kaiser und Reichstag halten, faktisch wurde ihnen aber im Friedensvertrag von 1648 die volle Landeshoheit zugestanden. Der Kaiser konnte nur noch in Ausnahmefällen in die inneren Angelegenheiten der Reichsstände eingreifen.

Franz Wilhelm von Hohenems, Landesherr in Hohenems und Vaduz, war an den Friedensverhandlungen nicht beteiligt und unterzeichnete den Vertrag auch nicht - wie die andern schwäbischen Reichsstände. Die Grafen von Hohenems wurden im Vertrag auch nicht erwähnt, sie mussten aber 3204 Reichstaler für die „Satisfaktion“ der Schweden aufbringen ${ }^{67}$ In Art. VIII $§ 1$ enthielt der Vertrag von Osnabrück die Bestimmung, dass sämtlichen Fürsten und Ständen des Reichs die alten Rechte und Privilegien bestätigt wurden und dass sie in der Ausübung ihrer „Landeshoheit“ von niemandem gehindert werden durften. ${ }^{68}$ Art. VIII $§ 2$ bestimmte, dass die einzelnen Reichsstände auch das Recht erhielten, Bündnisse unter sich und mit auswärtigen Mächten abzuschliessen, sofern diese nicht gegen den Kaiser, das Reich oder den Landfrieden gerichtet waren. Zwischen grossen und kleinen Reichständen wurde kein rechtlicher Unterschied gemacht. Der Vertrag steht somit am Anfang des Völkerrechts, das alle Staaten als gleichberechtigt anerkannte. Doch gilt es noch zu relativieren: Die Grafen von Hohenems waren nicht souverän im modernen Sinn, sie standen nicht ausserhalb des Reichs, sondern waren an die Reichsinstitutionen und an das Reichsrecht gebunden. Dies zeigte sich sowohl bei der Untersuchung der Hexenprozesse, die zur Absetzung des Graf Ferdinand Karl von Hohenems führte, wie auch beim Verkauf der Grafschaft Vaduz und der Herrschaft Schellenberg an Fürst Johann Adam I. von Liechtenstein. ${ }^{69}$

Gemäss den Staatsrechtslehrbüchern des ausgehenden 18. Jahrhunderts folgte aus der Reichsstandschaft automatisch die volle Landeshoheit. So schreibt Heinrich Gottfried Scheidemantel in seinem „Repertorium des Teutschen Staats- und Lehnrechts“: „Nach Vorschrift der angeführten Reichsgrundgesezze [!] steht also jetzt die Landeshoheit allen und

67 Stievermann, D.: Westfälischer Frieden, In: online eHLFL, https://historisches-lexikon.li/Westfälischer_ Frieden.

68 Vertrag von Osnabrück vom Oktober, online: https://de.wikisource.org/wik /Westfälischer_Friede_-_ Vertrag_von_Osnabrück.

69 Böhme, Ernst: Liechtenstein auf der schwäbischen Grafenbank. In: Liechtenstein - fürstliches Haus und staatliche Ordnung. Vaduz 1987, S. 293-310. 
jeden Reichsständen, und zwar in gleicher Maaße [!]zu, und es ist die Regel richtig: Wer Reichsstandschaft hat, hat Landeshoheit. "70 Nach Scheidemann behielt der Kaiser das Recht der „höchsten Oberaufsicht“ und schützte das Recht (auch der kleinen Reichsstände), er war aber nicht berechtigt, von sich aus in die Landeshoheit einzugreifen, dies konnte er nur bei Klagen der Untertanen tun. ${ }^{71}$

\section{Die Landammannverfassung}

Der Dualismus von Reich und Kaiser fand lokal im Dualismus von Landesherr und Landschaften eine Entsprechung. Zum Schluss soll dieses Thema hier noch kurz gestreift werden. Bereits unter den Freiherren von Brandis bildeten die beiden Herrschaften Vaduz und Schellenberg eigene Gerichtsgemeinden mit je einem Landammann und einem eigenen Gericht. Der Landammann wurde aufgrund eines Dreiervorschlags der Herrschaft an einer Landsgemeindeversammlung von den Untertanen gewählt. Die Landschaften konnten von der Herrschaftsausübung nicht ausgeschlossen werden, da es keine nennenswerte herrschaftliche Verwaltung gab. Herrschaftsübergreifende Institutionen gab es ausser dem Landesherrn keine, die Herrschaften und Landschaften funktionierten getrennt und wuchsen nie zu einem Land zusammen. Seit dem 17. Jahrhundert wurden die Rechte der Landschaften durch die zunehmend absolutistisch auftretenden Landesherren zurückgedrängt. Dies führte, vor allem im Bereich der Steuern und Abgaben, zwangsläufig zu vermehrten Konflikten zwischen den Landschaften und dem Landesherrn. Die Rechte der Landschaften in der Rechtsprechung wurden beschnitten und schliesslich ganz aufgehoben. Die Rechtsprechung wurde den herrschaftlichen Beamten übertragen, die ihr Amt an den amtlichen Verhörtagen im Schloss Vaduz ausübten die Landammänner waren noch Beisitzer. Die Landschaften suchten vergebens, ihre Rechte in der Rechtsprechung zurückzugewinnen. Bei den Huldigungen für die Fürsten von Liechtenstein in den Jahren 1699, 1712 und 1718 forderten sie nachdrücklich die Wiedereinführung der alten Landammannverfassung, doch liessen sich die Fürsten von Liechtenstein auf keine Verhandlungen ein. Mit der Erhebung der beiden Herrschaften zum Reichsfürstentum Liechtenstein im Jahr 1719 erfolgte der Durchbruch zum Absolutismus. Die beiden Landschaften wurden aufgehoben und durch das Reichsfürstentum ersetzt. Alle Hoheitsrechte waren in der Hand des Fürsten zusammengefasst.

\section{Zusammenfassung}

Das Reichsfürstentum Liechtenstein hatte Wurzeln im Spätmittelalter, als den Landesherren die ausschliessliche Gerichtsbarkeit in ihren Herrschaften und die Reichsunmittelbarkeit verliehen wurden. Diese Privilegien wurden ihnen vom Kaiser immer wieder

70 Scheidemantel, H. G.: Repertorium des Teutschen Staats- und Lehnrechts, Bd. 3, S. 29.

71 Scheidemantel, H. G.: Repertorium des Teutschen Staats- und Lehensrechts, Bd. 3, S. 35. 
bestätigt. Die Grafschaf Vaduz und die Herrschaft Schellenberg waren nacheinander im Besitz von vier verschiedenen Dynastien: Grafen von Werdenberg-Sargans zu Vaduz (1342-1416), Freiherren von Brandis (1416-1510), Grafen von Sulz (1510-1613) und Grafen von Hohenems (1613-1699/1712). Diesen war gemeinsam, dass sie fast immer treue Gefolgsleute des Kaisers waren und sich in kaiserlichen Diensten oder im Militär gute Einnahmen sichern konnten. Auch hohe Kirchenämter eröffneten mehrfach gute Perspektiven und die Möglichkeit, Verwandte zu begünstigen. Existenziell wichtig waren vorteilhafte Heiraten, aus denen sich beim Aussterben einer Dynastie Ansprüche auf das Erbe oder zumindest auf Teile davon ableiten liessen. Die verschiedenen Dynastien konnten sich jeweils nur etwa 100 Jahren halten. Dann gerieten sie aufgrund des kleinen Besitzes und ihrs aufwendigen Lebensstils in hohe Schulden und mussten - jeweils kurz vor dem Aussterben der betreffenden Linie - an ihre Verwandten verkaufen. Solche Verkäufe wurden durch Pfandschaften vorbereitet. Eine gezielte Territorialpolitik lässt sich bei keiner dieser Dynastien erkennen, es scheint vielmehr, dass sie sich von kurzfristigen Überlegungen leiten liessen. Die Werdenberg befehdeten sich sogar mehrfach in der eigenen Familie. Bis um 1510 gelang es den Freiherren von Brandis die landesherrlichen Rechte auszuweiten und zu festigen. Hervorzuheben sind die „Brandisischen Freiheiten" (in der erweiterten Fassung von 1492) und die Anerkennung als Reichsstand in den Reichsmatrikeln. Die volle Landeshoheit wurde jedoch erst mit der Erhebung der beiden Herrschaften Vaduz und Schellenberg zum Reichsfürstentum Liechtenstein erreicht. Erst die Fürsten von Liechtenstein vereinigten alle Rechte der Staatsgewalt in ihrer Hand.

\section{Resumé}

\section{Od přímé součásti Říše po říšskému knížectví - Kontinuity a diskontinuity}

Hrabství Vaduz a panství Schellenberg v údolí Rýna - mezi Švýcary a Habsburky - byla od středověku panstvími podřízenými bezprostředně císaři. Z hospodářského hlediska byla bezvýznamná: nenacházelo se tam ani žádné město. Pro jejich politický vývoj byl určující jednak rozpad větších panství a jednak postupné přibývání vrchnostenských práv. K prvnímu bodu jen tolik: v typickém případě držely v regionu různé dynastie několik panství, která však netvořila ucelený útvar. Jednotlivá panství spojovala jen osoba zeměpána (Personenverbandsstaat - státní útvar spočívající na osobních svazcích - pozn. překl.). Všichni držitelé se dostávali do hospodářských potíží a museli svá panství postupně rozprodávat. Komu prodali, záleželo většinou na příbuzenských vtazích (vzniklých v důsledku sňatků). Genealogickými aspekty se zde nemůžeme zabývat. Panství Vaduz a Schellenberg se nikdy nepokusili získat Habsburkové. Hrabata z Werdenberg-Sargansu ve Vaduzu (1342-1416). Werdenbergové měli zboží v údolí Rýna a v okolí Bodamského jezera. Při dělení dědictví mezi hrabata z Werdenberg-Sargansu v roce 1342 vzniklo panství Vaduz jako samostatné hrabství. K majetkům nové linie patřila kromě Vaduzu i část panství Schellenberg a také panství Sonnenberg a Blumenegg (dnes ve Vorarlbersku). Werdenbergové vykonávali vysoké i nízké soud- 
nictví, což bylo předpokladem pro vybudování zeměpanství. Udělení říšské bezprostřednosti císařem představovalo říšskoprávní legitimizaci jejich vyššího postavení. Není známo, kdy byla tato práva udělena poprvé, zachovala se pouze jejich pozdější potvrzení. V roce 1379 propůjčil král Václav Werdenbergům evokační právo (tzn. právní spory nesměly být přenášeny před královský soud). V roce 1396 jim potvrdil ř́řsskou bezprostřednost. Císařská privilegia byla vázána na držbu panství, mohla být ale spolu s panstvím odkázána v rámci dědictví a prodána. Werdenbergové nedělali cílevědomou teritoriální politiku, často byli vedeni krátkodobými zájmy.

Svobodní páni z Brandisu (1416-1510). Hrabata z Brandisu pocházela od Bernu, ve 14. století však přenesla své stěžejní zájmy do východního Švýcarska a okolí Bodamského jezera. Zde měla díky výhodným sňatkům a vlivu členů rodu, kteří zastávali významné církevní posty (biskup v Kostnici, opat v Reichenau) příznivé předpoklady. Brandisům se podařilo převzít velkou část majetkové držby vaduzských hrabat a pomocí několika přikoupených území ji dokonce ucelit. Z hlediska dějin Lichtenštejnska byla důležitá koupě chybějících částí panství Schellenberg (1434-1437), čímž došlo k ucelení území dnešního knížectví (a tento stav zůstal zachován dodnes). Pro vybudování zeměpanství to bylo důležité z dvojího hlediska: zaprvé získali Brandisové císařská privilegia (tzv. Brandisské svobody), jimiž byla potvrzena jejich práva v oblasti soudnictví. A zadruhé byly popsány hranice panství, do té doby často nejasné a sporné, a instalovány hraniční značky. Tím vzniklo jasně ohraničené území. Ke konci 15. století se rod dostal do hospodářských potíží a musel své majetky prodat. V roce 1512 svobodní páni z Brandisu vymřeli.

Hrabata ze Sulzu (1510-1613). Sulzové byli hraběcím rodem z jihozápadního Německa, jehož příslušníci zastávali vlivné úřady ve službách Habsburkủ (mj. úřad dvorského sudího v Rottweilu). Koupí panství Vaduz, Schellenberg a Blumenegg od svých příbuzných Brandisů v roce 1510 dosáhli svého vrcholu. Jako zeměpáni rozhodli, že budou mít všichni poddaní stejný status (nevolníci), výsadní práva „svobodných Walserů“ zrušili. Nárokovali si i náboženskou svrchovanost a zabránili tomu, aby se ve Vaduzu uchytila reformace. Novelizovali právní předpisy, a nárokovali si tedy i kompetence v zákonodárství (lesní řády, dědické právo aj.). V roce 1584 byla s oběma panstvími uzavřena dohoda o placení říšské daně („Schnitz“). Vrchnostenská správa zůstávala slabá i přesto, že si nárokovala větší vrchnostenská práva, což mělo především finanční důvody. Některé úkoly (např. výběr daní) byly přenechány jednotlivým oblastem (Landschaften) zastoupeným přednostou (Landamman). Sulzové měli hlasovací právo na hraběcí lavici sněmu Švábského kraje (Kreisstandschaft), ale nevykonávali ho.

Hrabata z Hohenemsu (1613-1699/1712). Hrabata z Hohenemsu byla držiteli stejnojmenného hrabství ve Vorarlbersku. Bohatství, vliv a moc získali Hohenemsové jako velitelé žoldnéřu a císařští úředníci. V roce 1613 koupil hrabě Kaspar panství Vaduz a Schellenberg. Jeho ctižádostivým cílem bylo vytvoření teritoriálního státu v údolí Rýna - což bylo možné jen na úkor Švýcarů a Habsburků. Podařit se to nemohlo. V 17. století vyschly př́ijmy Hohenemsů ze žoldnéřství. Hrabata si nadělala dluhy a nedostatek prostředků se pokusila sanovat čarodějnickými procesy. Kvůli dluhům na ně byla uvalena císařská nucená správa, nakonec ale nezbylo nic jiného, než prodat Lichtenštejnsko (1699/1712). Za hrabat z Hohenemsu bylo převedeno do písemné podoby místní zvykové právo (Landsbrauch) a policejní řád a vydány nové lesní řády. V roce 1614 byla s oběma panstvími obnovena smlouva o placení říšské daně. Tato smlouva způsobovala hrabatům z Hohenemsu značnou finanční újmu, Hohenemsové však nebyli schopni ji změnit ve svůj prospěch. Hraběcí správa zůstávala i nadále slabá - chyběly potřebné peníze. Na rozdíl od Sulzů a Brandisů využívali Hohenemsové právo účasti na krajském sněmu a vysílali na něj svého zástupce. 
